\title{
Orienting Head Movements Resulting from Electrical Microstimulation of the Brainstem Tegmentum in the Barn Owl
}

\author{
Tom Masino and Eric I. Knudsen \\ Department of Neurobiology, Stanford University, Stanford, California 94305-5401
}

The size and direction of orienting movements are represented systematically as a motor map in the optic tectum of the barn owl (du Lac and Knudsen, 1990). The optic tectum projects to several distinct regions in the medial brainstem tegmentum, which in turn project to the spinal cord (Masino and Knudsen, 1992). This study explores the hypothesis that a fundamental transformation in the neural representation of orienting movements takes place in the brainstem tegmentum. Head movements evoked by electrical microstimulation in the brainstem tegmentum of the alert barn owl were cataloged and the sites of stimulation were reconstructed histologically. Movements elicited from the brainstem tegmentum were categorized into one of six different classes: saccadic head rotations, head translations, facial movements, vocalizations, limb movements, and twitches. Saccadic head rotations could be further subdivided into two general categories: fixed-direction saccades and goal-directed saccades. Fixed-direction saccades, those whose direction was independent of initial head position, were elicited from the midbrain tegmentum. Goal-directed saccades, those whose direction changed with initial head position, were elicited from the central rhombencephalic reticular formation and from the efferent pathway of the cerebellum.

Particular attention was paid to sites from which fixeddirection saccadic movements were elicited, as these movements appeared to represent components of orienting movements. Microstimulation in the medial midbrain tegmentum elicited fixed-direction saccades in one of six directions: rightward, leftward, upward, downward, clockwise roll, and counterclockwise roll. Stimulation in and around the interstitial nucleus of Cajal (InC; a complete list of anatomical abbreviations is given in the Appendix) produced ipsiversive horizontal saccades. Stimulation in the ventral InC and near the dorsal and medial edges of the red nucleus produced upward saccades. Stimulation in the reticular formation near the lateral edge of the red nucleus produced downward saccades. Stimulation in the ventromedial central gray produced ipsiversive roll saccades. The metrics and kinetics of fixeddirection saccades, but not their directions, could be influenced by stimulation parameters. As such, direction was an invariant property of the circuits being activated, whereas

\footnotetext{
Received Apr. 8, 1992; revised July 16, 1992; accepted July 23, 1992.

We thank Dr. S. du Lac for providing useful comments on the manuscript and Phyllis Knudsen for assistance with the photographs. This research was funded by NSF grants ROI NS 27687-03 and T32 NS 07158-12.

Correspondence should be addressed to Tom Masino, Ph.D., Department of Neurobiology, Fairchild Science Building, Stanford University, Stanford, CA 943055401.

Copyright (c) 1993 Society for Neuroscience $0270-6474 / 93 / 130351-20 \$ 05.00 / 0$
}

movement latency, duration, velocity, and size each demonstrated dependencies on stimulus amplitude, frequency, and duration.

The data demonstrate directly that at the level of the midbrain tegmentum there exists a three-dimensional Cartesian representation of head-orienting movements such that horizontal, vertical, and roll components of movement are encoded by anatomically distinct neural circuits. The data suggest that in the projection from the optic tectum to these medial tegmental regions, the topographic code for orienting movement that originates in the tectum is transformed into this Cartesian code.

[Key words: optic tectum, superior colliculus, saccadic head movement, brainstem tegmentum, interstitial nucleus of Cajal, red nucleus, Cartesian code for movement, supraspinal microstimulation, coordinate systems]

Saccadic orienting movements center an object of interest in the visual field allowing attentional mechanisms to scrutinize the object in greater detail. These movements are carried out by the eyes, head, or body operating alone or in various combinations depending on the species and the behavioral situation. Although many neural circuits may participate in orienting movements, the pathway that contributes prominently in all vertebrates is the tectotegmental pathway (Grantyn and Grantyn, 1982; Huerta and Harting, 1982; Grobstein, 1988).

Information specifying a desired change in gaze is transformed several times as it is processed by the tectotegmental pathway. Visual input enters the optic tectum (superior colliculus) as topographically coded information in a retinocentric frame of reference. Eye and head position signals are combined with this information to yield a representation of object location that accounts for movements intervening between object detection and the orienting movement (Sparks and Mays, 1983; Sparks, 1986) and may allow for tectal control of saccade kinetics during movement (Munoz et al., 1991). The motor output code is a topographic representation of gaze error, the difference between the current direction of gaze and the direction of the object.

Topographic order is lost in the transformation that occurs next. Each portion of tectum exhibits the same pattern of efferent projection to midbrain and pontine motor structures (Grantyn and Grantyn, 1982; Masino and Grobstein, 1990; Masino and Knudsen, 1992). These tegmental structures, in turn, project to motor and premotor neurons in the brainstem and spinal cord, where ultimately a neural code is generated that causes coordinated contractions of the body musculature (Huerta and Harting, 1982; Masino and Grobstein, 1989a; Masino and Knudsen, 1992).

Some evidence suggests that a transformation that occurs in 
the tegmental portion of this pathway is the conversion of the gaze error signal from a topographic code into a Cartesian code in which the horizontal and vertical components of movements are represented by separate neural populations (Masino and Grobstein, 1989b; Masino and Knudsen, 1990). In the primate oculomotor system, tectal recipient neurons in the paramedian pontine reticular formation (PPRF; Raphan and Cohen, 1971; Keller, 1974; Sparks et al., 1987), and in the InC and rostral interstitial nucleus of the MLF (riMLF) (Buttner-Ennever and Buttner, 1978; Fukushima, 1987; Moschovakis et al., 1990), are involved in the generation of horizontal and vertical components, respectively, of saccadic eye movements. That saccadegenerating circuits for these particular directions exist for primate eye movement control is not surprising, since the pulling directions of the extraocular muscles define a similar coordinate system. However, saccade-generating circuits that underlie oricnting movements of the head or body also appcar to have a tegmental representation in which the horizontal component of movement is encoded separately (Kostyk and Grobstein, 1987; Grobstein, 1988; Masino and Grobstein, 1989b; Masino and Knudsen, 1990; Masino, 1992). In contrast to the primate oculomotor system, there is essentially no orthogonality in the skeletomuscular systems that mediate these movements.

When barn owls make orienting head movements, Inost of the movement is carried out by rotation of the head, since the cylindrical eyes are able to rotate by only a few degrees (du Lac and Knudsen, 1990). Previous experiments in the barn owl have shown that between the topographic code for orienting movement in the optic tectum and the motorneuron code for muscle tension in the cervical spinal cord there exists a code in which the upward, downward, leftward, and rightward components of head movement are represented by functionally distinct saccade gencrators (Masino and Knudsen, 1990). However, the experiments gave no hint as to where in the posttectal pathway the transformation into this Cartesian representation occurred. To determine whether a Cartesian representation of head movement exists within the tectotegmental-spinal pathway, we studied the movements that were elicited by electrical microstimulation in the medial brainstem where tectal efferent projections overlap with spinal afferent neurons (Masino and Knudsen, 1992). The results demonstrate that activating particular portions of this region elicits saccadic head movements specifically in the horizontal, vertical, or roll direction, depending on the site of stimulation. Moreover, the regions from which Cartesian components of saccadic head movements can be elicited are similar to those that produce horizontal and vertical components of saccadic eye movements in primates.

\section{Materials and Methods}

The preparation. Three adult barn owls (Tyto alba) were used in these experiments. Microstimulation was carried out using a head-mounted microdrive capable of movement in three dimensions. A dovetailed base for the microdrive $(12.5 \mathrm{gm})$ was attached permanently to the skull by the following procedure. The owl was anesthetized with halothane and nitrous oxide. The scalp was treated with betadine antiseptic agent, the dorsal cranial surface was exposed, and the edges of the wound were infused with lidocaine. A bolt for securing the head in a stereotaxic device was cemented to the skull. A rectangular opening $(8 \mathrm{~mm} \mathrm{me}-$ diolateral and $14 \mathrm{~mm}$ rostrocaudal) was made through skull. The dura was removed with scissors, and chloramphenicol solution was applied to the surface of the brain to prevent infection. The owl was placed in a stereotaxic device, and the head was positioned so that the projections of the dorsolateral edges of the pectin oculi were oriented $12^{\circ}$ below the horizon. This head position leveled the dorsal surface of the brain and oriented the midbrain so that the electrode trajectory was normal to the neuraxis. The microdrive base was centered over the cranial opening and was cemented in place with dental acrylic. After securing the microdrive base to the skull, mineral oil was placed on the surface of the brain and molten bone wax was used to seal the opening. Skin flaps were sutured tightly around the microdrive base and were covered with betadine solution, and the animal was allowed to recover.

Every other day for the next 2-3 weeks, stimulation experiments were performed. The owl was anesthetized briefly using halothane and nitrous oxide, wrapped securely in a chamois cloth to restrict limb movements, and placed in a tube that allowed the head to move freely. The owl was centered in a room that contained electromagnetic induction coils. A search coil was bolted to the top of the skull so that the plane of the search coil was orthogonal to the owl's visual axes. The bone wax was removed from the cranial opening, the opening was filled with antibiotic solution, and the microdrive was mounted onto the dovetail base. Lidocaine was injected into the skin around the microdrive base, and current return and ground leads were attached.

Microstimulation. Stimulation electrodes consisted of electrolytically etched, epoxy-coated tungsten rods. The exposed electrode tips were 12-15 $\mu \mathrm{m}$ long and 4-6 $\mu \mathrm{m}$ wide at the base. Constant-current, electrically isolated stimulus pulse trains were generated by a Grass S88 stimulator and model PSIU6 stimulus isolation units. The search mode stimulus consisted of $150 \mu \mathrm{sec}$ cathodal, followed immediately by 150 $\mu \mathrm{sec}$ anodal, pulses at $200 \mathrm{~Hz}$ for $40 \mathrm{msec}$. The current strength was $100 \mu \mathrm{A}$. According to current-distance studies by Ranck (1980), 100 $\mu \mathrm{A}$ passing through an electrode of the size used in these studies would have activated axons at a distance ranging from $1000 \mu \mathrm{m}$ for lowthreshold neurons to $300 \mu \mathrm{m}$ for high-thrcshold ncurons.

The brains were surveyed systematically from rostral to caudal. At each rostrocaudal level, starting at the caudal thalamus, a series of six to nine electrode penetrations were made at $500 \mu \mathrm{m}$ mediolateral intervals. The electrode was then moved caudally $500 \mu \mathrm{m}$, and the series was repeated. Up to $7 \mathrm{~mm}$ in rostrocaudal extent was surveyed in this manner.

The electrode was advanced in $100 \mu \mathrm{m}$ steps during the search mode. Upon eliciting a movement, the current was adjusted down to levels that caused a $15^{\circ}\left( \pm 5^{\circ}\right)$ amplitude movement. Movements in this range could be elicited more consistently than larger movements. Throughout the regions producing head rotations, the electrode was advanced in 20 $\mu \mathrm{m}$ steps.

The anatomical site associated with a given movement was determined by adjusting the current so that the movement amplitude produced from a location was similar to that produced from the previous location. At the first site where it was necessary to increase the current level to evoke the same movement, the movement was characterized (withdrawal of the electrode to a previous site was found to require higher current levels to evoke the same movement). Thus, a reconstructed site for eliciting a movement represents the ventral border of a region where the lowest current levels produced the movement.

Characterization of movements. The horizontal and vertical components of movements (search coil output) were digitized at $1 \mathrm{kHz}$, displayed, and saved on a mass storage device for further analysis. Search coil output was calibrated using a two-dimensional protractor. Horizontal position was defined as the degree of rotation relative to the midsagittal plane of the body, $90^{\circ}$ being rightward and $-90^{\circ}$ being leftward. Vertical position was defined as the degrec of rotation relative to the horizontal plane passing through the center of the head, with $90^{\circ}$ being straight up and $-90^{\circ}$ being straight down.

At each site in the brain from which saccadic head movements were elicited, movements were measured with the head starting from various positions. Typical initial head positions were spaced at approximately $10^{\circ}$ intervals in both azimuth and elevation from primary position $\left(0^{\circ}\right.$ elevation, $0^{\circ}$ azimuth). The head was coaxed into various initial positions with a soft noise, usually two fingers rubbed together. For most stimulation sites, the movement amplitude, trajectory, and velocity profile tended to degrade after several movements were elicited. The degradation seemed to result from changes in neural responsiveness, as opposed to changes in electrode characteristics, because moving the electrode to a new movement site again resulted in movements with normal properties.

Programs that calculated velocity profiles, latency, duration, direction of movement, and other aspects of movement were applied to each trace and the results were tabulated. Representations of horizontal and vertical velocities were generated by first smoothing the position trace using a centered running train average, over $7 \mathrm{msec}$, weighted according to a 

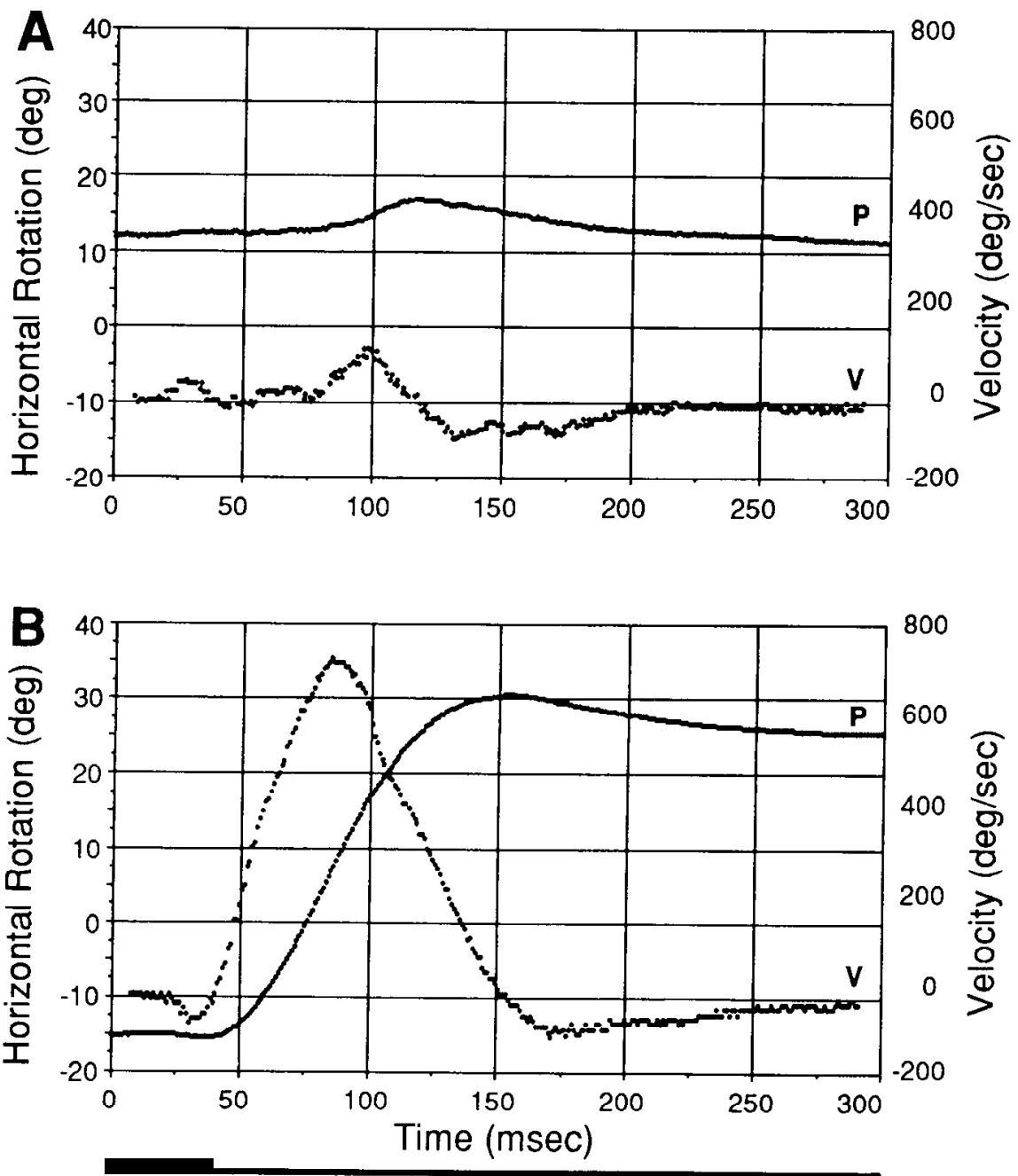
Stim
800

600

Figure 1. Position and velocity profiles following stimulation at a fixeddirection (upward) saccadic movement site in the mesencephalic tegmentum. The stimulus pulse train (Stim) is represented at bottom of each graph. $A$, Position $(P)$ versus time for the horizontal component of movement: velocity $(V)$ versus time for the horizontal component. $B$, Position $(P)$ versus time for the vertical component of movement; velocity $(V)$ versus time for the vertical component. Velocity was computed as a difference of Gaussians for $1 \mathrm{msec}$ differences of position data.
Gaussian distribution. Velocity was derived from differences between adjacent points in the smoothed position traces. This method did not introduce phase shifts, nor did it alter the velocity profile or the maximum velocity by more than $1 \%$. Movement onset was the time and location at which head velocity exceeded 1.5 times the maximum velocity in the $15 \mathrm{msec}$ prior to stimulation (baseline velocity). Movement endpoint was the time and position at which velocity returned to within 1.5 times the baseline velocity. Latency was the time between stimulation onset and movement onset. Duration was the time between onset and endpoint. Direction was the arctangent of the difference between the onset and endpoint positions; directions were defined in a polar coordinate system in which $0^{\circ}$ indicated a vertical upward movement, $90^{\circ}$ a purely rightward movement, $-90^{\circ}$ a leftward movement, and $180^{\circ}$ or $-180^{\circ}$ a downward movement. Standard deviations of direction for a single site were calculated from movements starting at various head positions.

The search coil in its standard orientation on the head was not sensitive to head roll (rotations around the visual axis) or to translational movements. In order to record roll movements, the search coil was rotated $90^{\circ}$ so that it was parallel to the midsaggital plane of the head.

Localization of stimulation sites. Marking lesions were made in order to assess the anatomical structures being activated. Lesions were made by passing $10 \mu \mathrm{A}$ of direct current (electrode negative) for $15-25 \mathrm{sec}$. Similar regions of the brainstem were surveyed in the three birds. Nomenclature for cell groups is based on related anatomical studies (Masino and Knudsen, 1992). The surveys extended rostral to midthalamic levels, including the medial and dorsal posterior thalamic nuclei, internal and external stratum cellulare (SCE), nucleus ovoidalis, and the posterior hypothalamic nuclei. In two cases (owls 2 and 3), the penetrations extended laterally to include the medial portions of the nucleus rotundus on one side. Farther caudal, the stimulated region included the medial pretectal nuclei including the pretectal nucleus (PT), the medial and lateral spiriform nuclei, and the pretectal gray. Also stimulated in each case were the three fiber systems, the occipitomesencephalic tract (OM), which carries fibers from the hyperstriatal regions of the telencephalon to the medial midbrain and rhombencephalic tegmental regions and the spinal cord; the quintofrontalis tract (QF), carrying fibers from the principle trigeminal nucleus to nucleus basalis in the basal forebrain; and the ansa lenticularis (AL), with fibers connecting the caudate nucleus to the ventral thalamus. At midbrain levels, the stimulated area extended laterally to include all or parts of the OM and QF. The stimulated area covered the entire dorsoventral extent of the brain through these regions. In owls 1 and 2 , the stimulated region extended caudally to midpontine levels. In owl 3 , the stimulated region extended to the level of the vestibular nuclei, including the entire nucleus reticularis pontis gigantocellularis ( $\mathrm{RPgc}$ ). Laterally the stimulation zone covered only the RPgc and did not include the more laterally situated principal trigeminal or facial nuclei.

Upon completing a survey, each bird was deeply anesthetized with sodium pentobarbital. Heparin sulfate $(0.3 \mathrm{ml})$ was injected into the heart, and the owl was perfused with buffered saline containing lidocaine, followed by $10 \%$ formalin. The brain was removed and cut in the plane of the electrode penetrations, mounted on glass slides, and stained with cresyl violet. The sections containing lesions were drawn using a camera lucida, and the locations of stimulation sites were reconstructed on the basis of these lesions.

\section{Results}

Classification of clicited movements

An initial survey revealed that many different kinds of motor output could be elicited by electrical microstimulation of dif- 

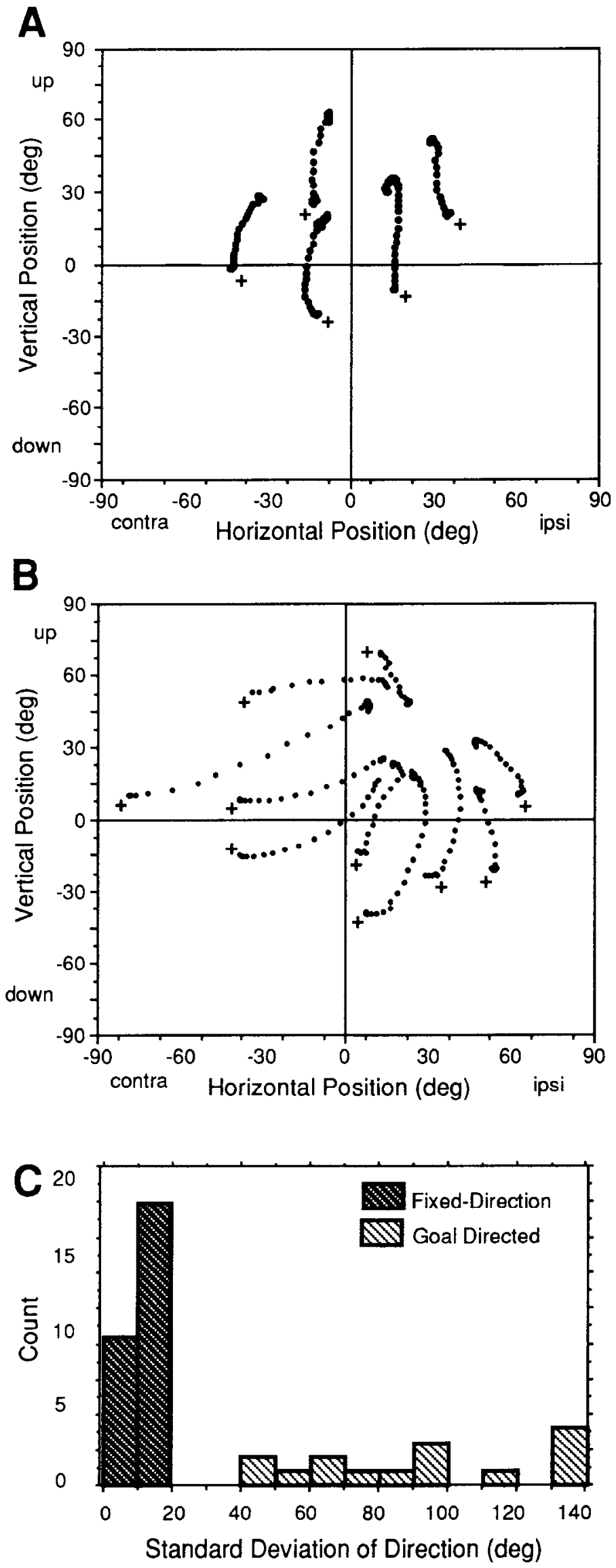

ferent sites in the brainstem tegmentum. These motor outputs were categorized into six major classes: saccadic head rotations, head translations, facial movements, vocalizations, upper or lower limb movements, and twitches. Of these, saccadic head rotations stood out as being similar to orienting head movements. Therefore, although all types of movement were cataloged, we focused our attention on saccadic rotations and the sites from which they could be elicited.

To qualify as a saccadic head rotation, a movement had to be a quick rotation of the head (maximum velocity $>200 \% / \mathrm{sec}$ ), exhibit a symmetric velocity profile, and end with the head maintained in a new position (Fig. 1). Movements that satisfied these criteria could be grouped into two distinct classes based on the effect of the initial head position on the direction of the saccade. Fixed-direction saccades were those made in essentially the same direction regardless of initial head position (e.g., Fig. $2 A$ ). Goal-directed saccades changed direction substantially with initial head position (e.g., Fig. 2B). The distinction between these two classes of movement was made on the basis of the SD of movement direction when initial head position was varied over a wide range (see Materials and Methods). As shown in Figure $2 C$, SDs for fixed-direction and goal-directed saccades fell into discontinuous ranges.

Fixed-direction saccades were themselves divisible into six subgroups based on the direction of movement: rightward, leftward, upward, downward, clockwise roll, and counterclockwise roll. Roll saccades contained little or no horizontal or vertical rotation and therefore form discrete subgroups. All other fixeddirection saccades were directed predominantly horizontally or vertically with occasional exceptions (Fig. 3). As described below, these exceptions were diagonally directed, contraversive saccades that resulted from stimulating the output pathway of the optic tectum; they were not elicited from the tectospinal overlap zones in the medial tegmentum.

Goal-directed saccades were not divisible into discrete subgroups. Instead, the basic characteristics of these movements, such as the precision and location of the goal position, varied widely across stimulation sites.

\section{Spatial resolution of stimulation sites}

Microstimulation at most sites in the tegmentum evoked smallamplitude twitches of the head or body (using the standard search stimulation parameters; see Materials and Methods). As the electrode advanced toward a movement-eliciting zone, movements belonging to one of the six major classes of movement typically appeared abruptly over nominal electrode distances of 100-200 $\mu \mathrm{m}$. The distance of electrode advance over which a given class of movement persisted was highly variable, ranging from 50 to $1200 \mu \mathrm{m}$. As the electrode passed through

\footnotetext{
Figure 2. Distinction between fixed-direction and goal-directed head saccades based on the variation of movement direction with changes in initial head position. $A$, Example of five upward saccadic movements elicited from a fixed-direction site in the mesencephalic tegmentum. Pluses are placed next to initial head positions. Each data point represents the position of the head at $5 \mathrm{msec}$ intervals. $B$. Similar representations of 10 movements elicited from a goal-directed site in the rhombencephalon. $C$, Frequency histogram of SDs of movement direction. SD was calculated from five or more movements from different starting head positions. Movements that varied little in direction (SD $<20^{\circ}$ ) were classified as fixed direction; movements that varied greatly in direction $\left(\mathrm{SD}>40^{\circ}\right)$ were classified as goal directed.
} 


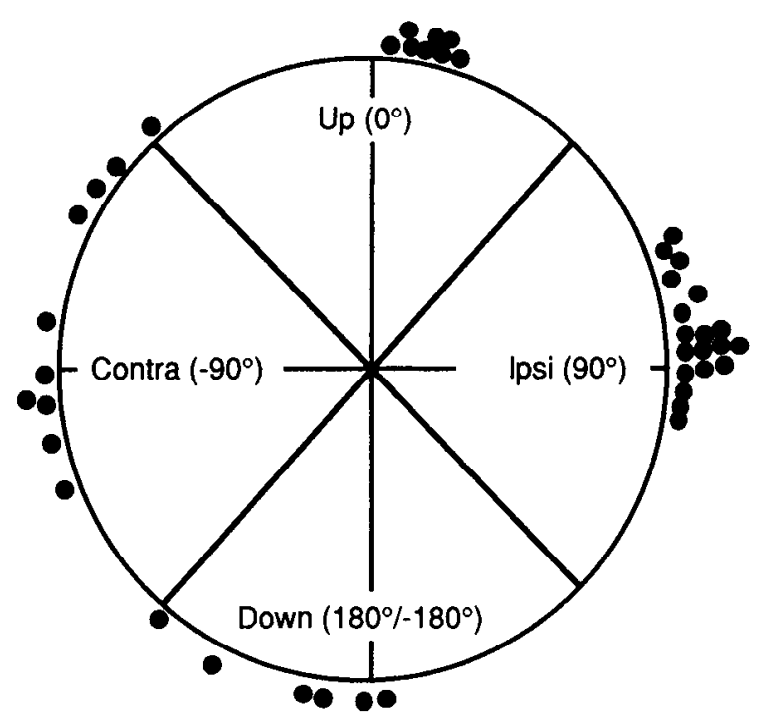

Figure 3. Average direction of fixed-direction saccades from each tegmental stimulation site. Each circle represents the average movement direction for all movements elicited at a single tegmental site. Ipsiversive movements (e.g., rightward movements from stimulating the right side of the brainstem) clustered around the horizontal direction $\left(90^{\circ}\right)$, while contraversive movements $\left(-90^{\circ}\right)$ lacked clustering. Sites producing contraversive movements were located farther laterally in the tegmentum and in most cases were associated with regions of tectal efferent pathway. A second clustering occurred for the upward direction and a third near downward.

a movement zone, the current level required to elicit the movement usually dropped sharply, to levels as low as $15 \mu \mathrm{A}$, and then gradually increased as the electrode moved beyond the movement zone.

Movement-eliciting zones for the six major classes of movement were discrete and separated from each other by nominal distances of $200 \mu \mathrm{m}$ or more. In contrast, movement zones for different subclasses of fixed-direction saccadic head rotations often occurred together, separated by extremely short distances: fixed-direction saccades could change from roll to horizontal or from upward to downward with a single $50 \mu \mathrm{m}$ advance of the electrode (Fig. 4); a change from horizontal saccades to upward saccades could occur over a distance of as little as $150 \mu \mathrm{m}$ of electrode advance. When movement zones representing different fixed-direction saccades were separated by greater distances, advancing the electrode caused saccades in one direction to decrease in amplitude and sometimes to disappear altogether, and then saccades in the second direction would appear abruptly. Intermediate directions of head saccades were not evoked from these intervening areas.

\section{Fixed-direction saccadic head movements: horizontal}

Localization of sites. Figures 5-7 are camera lucida reconstructions, based on lesioned sites (Fig. 8), from three animals showing locations at which fixed-direction head saccades were evoked. Horizontal head saccades, represented by horizontal arrows, were elicited from a total of 52 different sites.

Figure 5 shows reconstructed stimulation sites in ow 1 , in which 13 horizontal saccade sites were identified. In this and the other two birds, the horizontal sites clustered in three general regions. The dorsomedial region comprised the dorsomedial portion of the rostral midbrain tegmentum, including the InC and the nucleus Darkschewitsch (Dk). The ventral dorsomedial

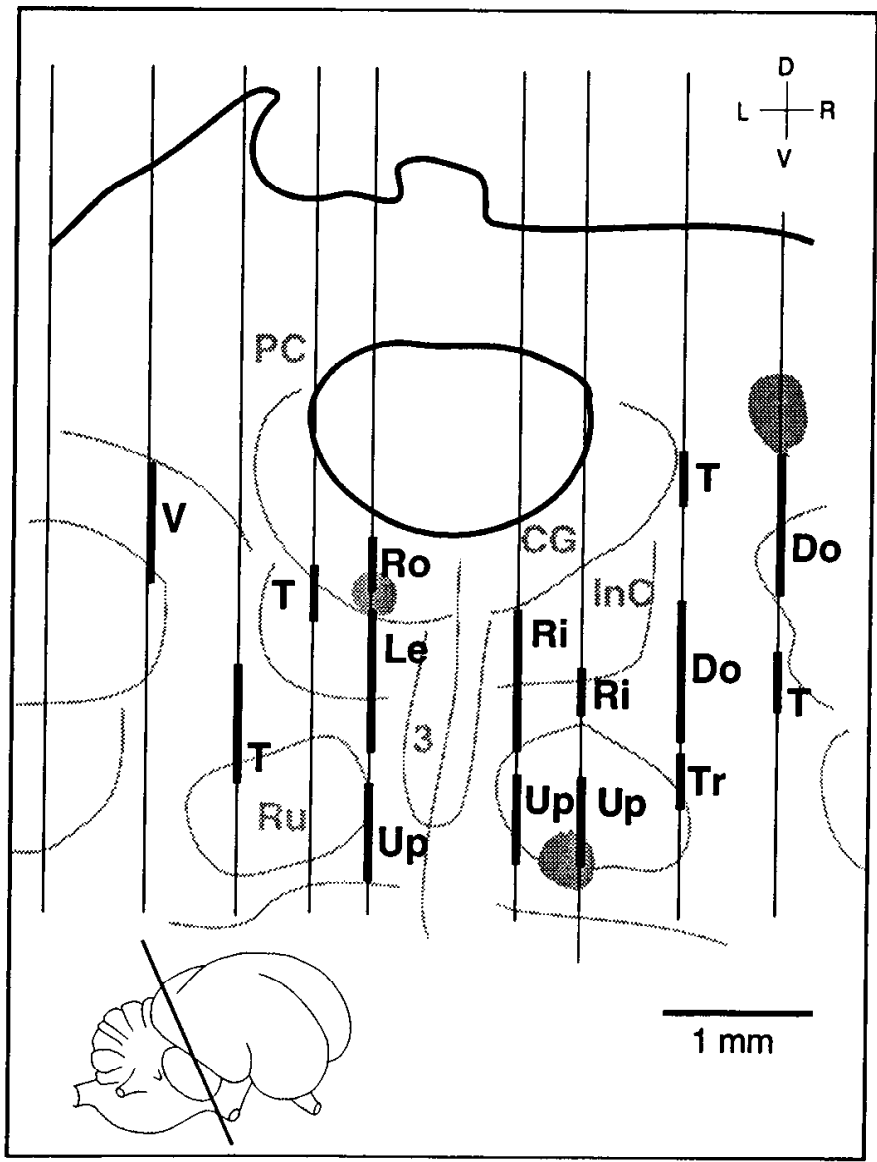

Figure 4. A cross section through the rostral mesencephalic tegmentum showing locations of electrode penetrations (thin vertical lines) and regions from which various motor behaviors were elicited (thick vertical lines). General movements include $V$, vocalization; $T$, twitch; and $T r$, translation. Fixed-direction saccades include $R o$, counterclockwise roll; $L e$, left; $R i$, right; $U p$, up; $D o$, down. The inset shows the plane of section on a lateral view of the brain. See Appendix for anatomical abbreviations for Figures 4-8.

region was slightly more ventral and caudal in the midbrain, located just below the oculomotor nucleus and the MLF. The lateral region was the portion of the midbrain and rostral rhombencephalic tegmentum just lateral to the red nucleus and in the tectal efferent bundle. In owls 1 and 3 (Figs. 5, 7), most of the horizontal sites were located in the dorsomedial region (Figs. $5 B, C ; 7 B-D$ ). All of the saccades elicited from these sites were directed toward the side ipsilateral to the site of stimulation. Several horizontal sites were found in the ventral dorsomedial region (Figs. $6 A, B ; 7 C, D$ ), just medial to the exiting oculomotor nerve, a region composed mainly of medium- and large-diameter fibers running rostrocaudally. The saccades elicited from this region were also directed ipsilaterally to the site of stimulation. Compared with the movement zones in the dorsomedial region, the movement zones in this region were on average half as large in dorsoventral extent and were sometimes located immediately adjacent to movement zones for vertical fixed-direction saccades.

In contrast to the fixed-direction saccades elicitcd from the medial regions, fixed-direction saccades elicited from the lateral midbrain tegmentum were variously directed. For example, at one site just caudal and lateral to the red nucleus, ipsilateral horizontal saccades were similar to those observed in the medial 

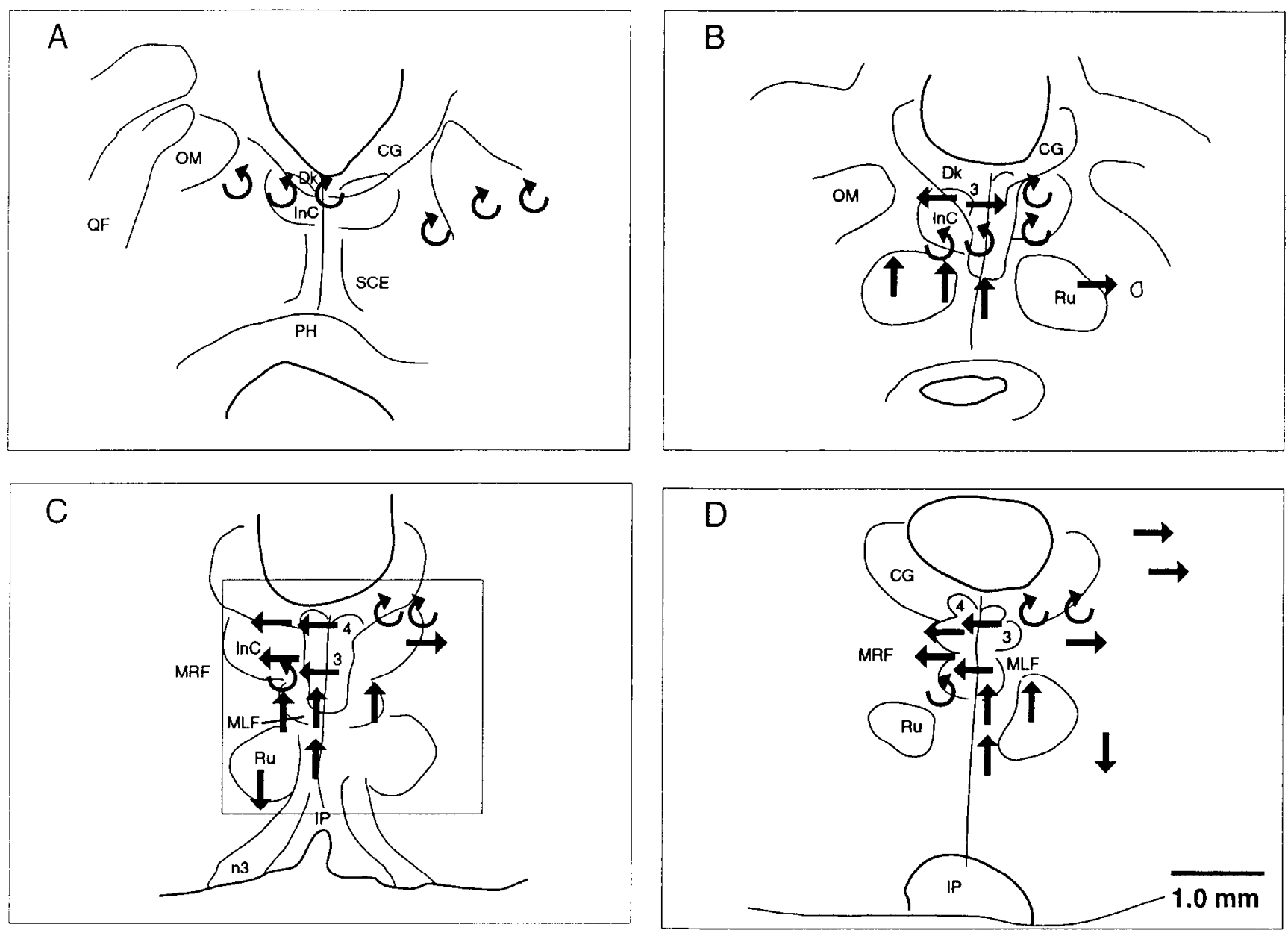

Figure 5. Camera lucida drawings of transverse sections through the rostral and central mesencephalic brainstem tegmentum in owl 1 indicating stimulation sites that produced fixed-direction saccades. Arrows are centered at the sites from which lowest currents yielded complete movements. The direction of the arrow indicates the category of fixed-direction movement elicted from that location. Circular arrows represent locations from which roll movements in either the clockwise or counterclockwise direction were elicited. $B O x$ in $C$ represents frame of photomicrograph in Fig. $8 B$.

regions (Fig. $6 B$, rightmost rightward arrow). However, at three other sites (leftward arrows, Fig. $6 A, B$ ) the movements were fundamentally different: they were contraversive relative to the site of stimulation, the direction of the saccade could change to diagonal directions with small advances of the electrode, and the minimum latency to movement was $21 \mathrm{msec}$, which was longer than the $19 \mathrm{msec}$ minimum latency measured for medial sites (see below). These properties would be expected of saccades elicited by tectal efferent stimulation (du Lac and Knudsen, 1990), and indeed, these sites were localized within the densest part of the tectal efferent bundle (Masino and Knudsen, 1992).

In owl 2, 17 sites were found from which horizontal saccades were elicited; in owl 3, 22 such sites were studied. The locations of the sites from these animals (Figs. 6,7) were consistent with the pattern described for owl 1. Figure $7 D$ shows medial sites in owl 3 that were located farther ventral and caudal than in either of the other cases. These represent the most caudal locations from which horizontal fixcd-direction saccades were elicited.

A compilation of the data from these three cases indicated that ipsiversive horizontal fixed-direction head saccades were consistently associated with structures close to the midline, in and around the InC. The region extended from the rostral border of the midbrain to the rostral end of the trochlear nucleus in the rhombencephalon and mediolaterally from the midline to regions up to $500 \mu \mathrm{m}$ lateral to the InC. More laterally, in the region of the tectal efferent bundle, contraversive saccades predominated, although occasional ipsiversive saccades were observed at sites just lateral to the red nucleus.

Effects of initial head position. Figure 9 illustrates the effect of changing the initial head position on the metrics of ipsiversive horizontal fixed-direction saccades. Movements elicited from a site in each of the three tegmental regions are shown. In gathering these data, initial head positions ranging from $40^{\circ}$ ipsilateral to $40^{\circ}$ contralateral and from $+30^{\circ}$ to $-40^{\circ}$ were routinely sampled (see Materials and Methods); data were saved only for those initial head positions for which stimulation rcsulted in head movement. One difference between the movements elicited from sites in the medial tegmentum (Fig. 9A-C) and those elicited from the lateral tegmentum (Fig. $9 D$ ) is apparent: stimulating medial sites elicited ipsiversive saccades only when the head started in a position that was turned toward the contralateral side (relative to the site of stimulation) or up to $25^{\circ}$ toward the ipsilateral side. Initial head positions more than $25^{\circ}$ ipsilateral resulted in shuddering movements of the head, but no net rotations. In contrast, stimulation of sites in the tectal efferent bundle (that resulted in contraversive saccades) evoked saccades 

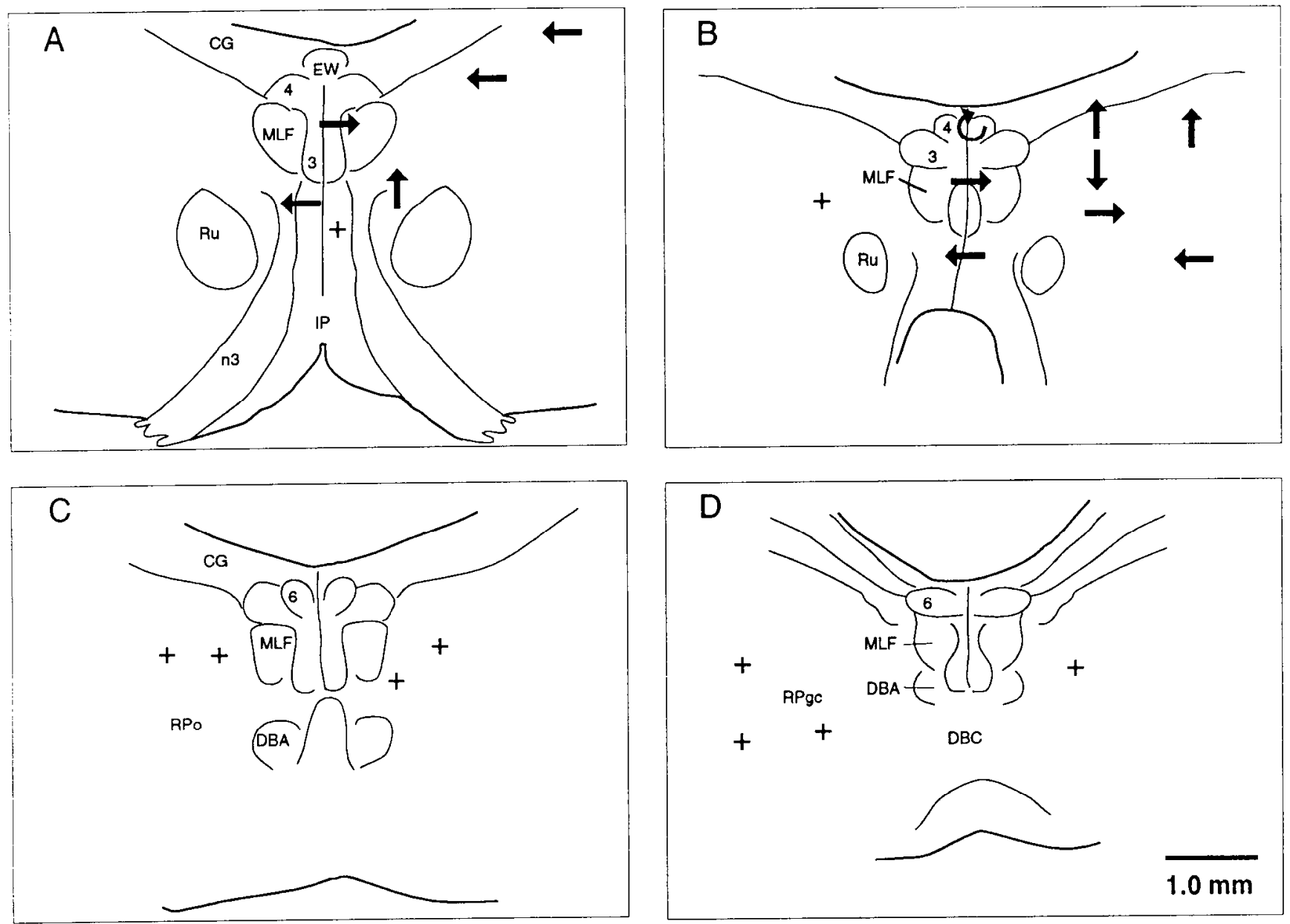

Figure 6. Camera lucida drawings of tranverse sections through the medial mesencephalic and rhombencephalic brainstem tegmentum of owl 2 showing stimulation sites that produced fixed-direction and goal-directed saccades. $A-D$ show midmesencephalic through rostral rhombencephalic levels. Pluses represent locations from which goal-directed movements were elicited. See Figure 5 for details.

of diminishing, but measurable amplitude out to initial positions of $40^{\circ}$ ipsilateral (Fig. 9D).

The effect of initial head position on kinetic and metric parameters of movement are shown in Figure 10 for 18 horizontal saccade stimulation sites in the dorsomedial and ventral dorsomedial regions. Mean directions for these sites ranged from $65^{\circ}$ to $100^{\circ}$ ipsilateral (polar coordinates; Fig. 3). As is inherent to the definition of this class of movement, there was little change in the horizontal or vertical component of saccade direction with changes in initial head position (Fig. 10A,B). In contrast, the ranges of saccade size (Fig. 10C) and velocity (Fig. $10 D$ ) varied greatly with initial head position, even though stimulation parameters were held constant. Large-size (up to $30^{\circ}$ ) and high-velocity (up to $450 \% \mathrm{scc}$ ) saccades were clicited from some sites, but only when the head started in a position turned toward the side contralateral to the stimulation site. For centered initial head positions, the range of saccade sizes and velocities decreased to about $50 \%$ of this range. The change in the range resulted from a dependency of size and velocity on initial head position for those stimulation sites capable of generating large saccades (Fig. 10C,D). These sites were all localized in the dorsal InC. For other sites, the elicited saccades remained relatively small and slow regardless of initial head position. These sites tended to be located outside the InC. Saccade duration and latency exhibited substantial variability across trials and showed no obvious trends with respect to initial head position (Fig. $10 E, F)$; the minimum latency for ipsiversive saccades was 19 msec.

The interrelationship among three movement parameters (size, maximum velocity, and latency) across all stimulation sites and across all initial head positions is illustrated in Figure 11. Smaller movements tended to be slower and to display long latencies, whereas larger movements tended to be faster with shorter latencies. The points form a single continuous distribution, suggesting that the interrelationship stems from mechanisms that operate subsequent to the site of stimulation.

Of all the parameters of movement measured, the direction of movement was the one that remained essentially constant across all trials.

Effect of stimulation parameters. The influences of stimulation current level, pulse frequency, and train duration on the metrics and kinetics of horizontal fixed-direction saccades are shown in Figure 12 for two sites in the dorsal InC and for one site outside the InC but still within the dorsomedial region in three owls. Movement size, latency, maximum velocity, and duration changed essentially as continuous functions of each stimulus parameter over the ranges tested. Movement direction (not shown) was the only parameter of movement that was not altered systematically by changes in any of these stimulation parameters. 

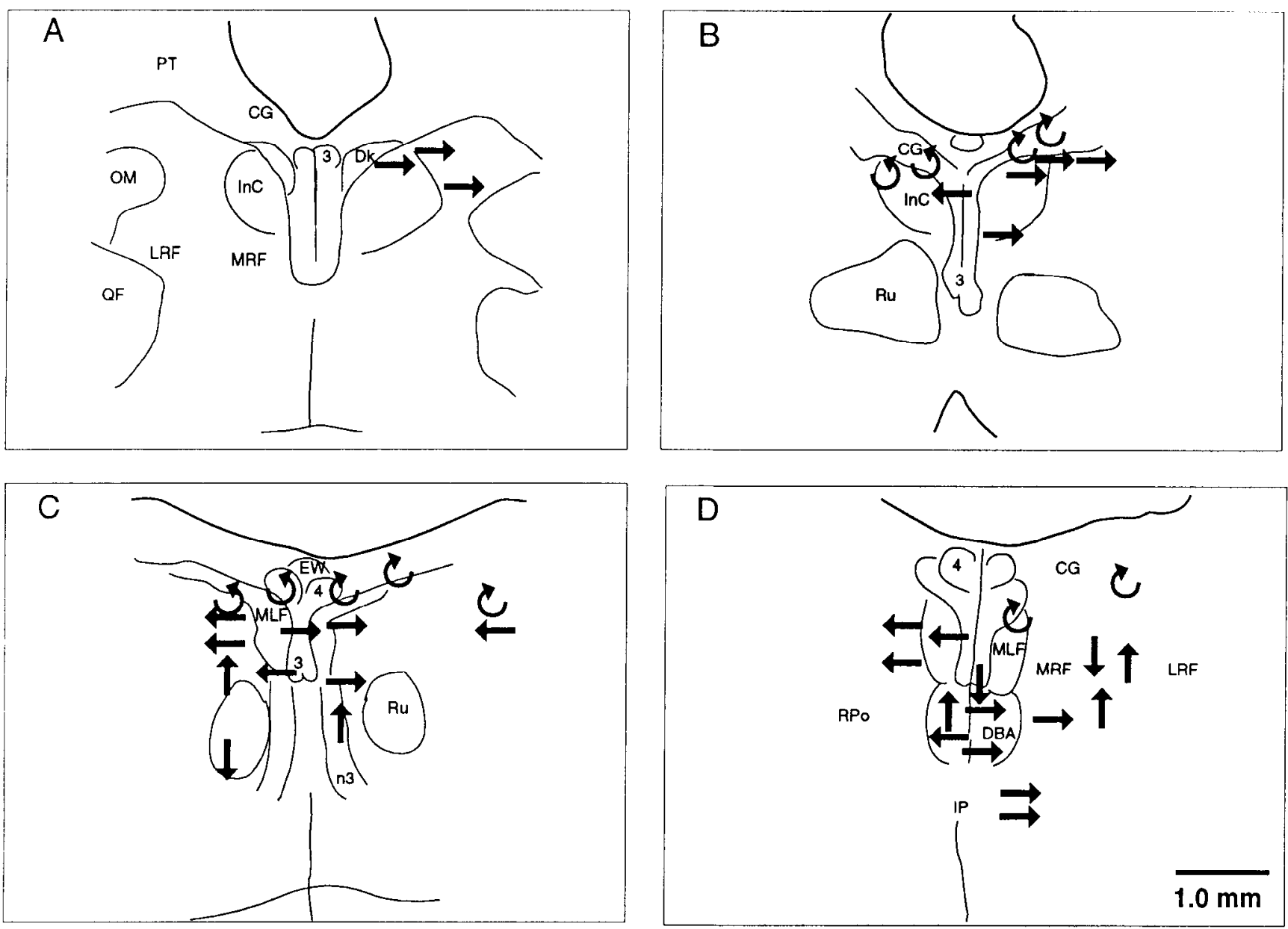

Figure 7. Camera lucida drawings of tranverse sections through the mesencephalic and rhombencephalic brainstem tegmentum in owl 3 indicating stimulation sites that produced fixed-direction saccades. See Figure 5 for details.

Train duration was the one stimulation parameter that could alter the shape of the velocity profile. Pulse trains shorter than 60 msec evoked saccades with normal, symmetric velocity profiles (e.g., Fig. 1B). Longer pulse trains prolonged the deceleration phase of the saccade, resulting in an asymmetric velocity profile and a distinctly abnormal appearance to the saccade.

\section{Fixed-direction saccadic head movements: upward}

Localization of sites. Fixed-direction upward saccades were elicited from 26 stimulation sites in the three owls. The locations of these sites are plotted in Figures 5-7 as upward arrows. In general, upward saccades were elicited from a region just ventral to the dorsomedial region from which horizontal saccades were elicited. In four penetrations, upward saccade sites were encountered 100-200 $\mu \mathrm{m}$ below horizontal saccade sites. Five of the upward sites were located in the red nucleus $(\mathrm{Ru})$ and 14 more were within $250 \mu \mathrm{m}$ of the $\mathrm{Ru}$, distributed along the dorsal or medial edges of the nucleus. One upward site was nested among horizontal and downward movement zones in the caudal midbrain tegmentum just below the MLF (Fig. 7D). The remaining six sites were in the tectal efferent bundle located laterally in the tegmentum, outside the tectospinal overlap region. In summary, the majority of sites were localized in the region extending from just caudal of the rostral end of $\mathrm{Ru}$ to the caudal end of the $\mathrm{Ru}$, below and caudal to the $\mathrm{InC}$, and within $1 \mathrm{~mm}$ of the midline.
Effect of initial head position. Upward saccades could be elicited from all initial head positions. Figure 13 shows examples of movement trajectories for two sites. In Figure 13 $\mathrm{A}$, the data shown are from a site that exhibited high directional constancy $\left(\mathrm{SD}=7.8^{\circ}\right)$; in Figure $13 B$, the data are from a site exhibiting low directional constancy $\left(\mathrm{SD}-15.6^{\circ}\right)$. The mean directions (see Materials and Methods) across all upward sites ranged from $2^{\circ}$ to $16^{\circ}$ ipsilateral (polar coordinates, $0^{\circ}=$ straight up; Fig. 3 ).

The effect of initial head position on various metric and $\mathrm{ki}$ netic properties of the upward saccades was tested extensively at eight different sites. As with horizontal saccades, the direction of movement was the only aspect that was predictable across initial head positions and across stimulation sites (Fig. 14). There was a tendency for the direction of upward saccades to tilt slightly toward the midsagittal plane of the body when the head started from an eccentric horizontal position (Fig. 14B). Otherwise, saccade direction was essentially independent of initial head position.

Saccade size, maximum velocity, duration, and latency of upward fixed-direction saccades exhibited similar dependencies on initial head position as we described for horizontal saccades (Fig. 10C-F). There was site to site variability in the size of the upward saccade that could be elicited from a given tegmental region. For those sites from which large saccades could be elicited, most of which were located in or adjacent to the $\mathrm{Ru}(n=$ $6)$, size, velocity, and duration tended to increase and onset 
latency tended to decrease as the initial position of the head was positioned farther downward. The relationship between size, maximum velocity, and latency for the data collected from the eight upward sites in three birds defined a single continuous distribution, as it did for the horizontal sites (Fig. 11).

Effect of stimulation parameters. The effects of stimulation current level, pulse frequency, and burst duration were tested at two sites in the medial Ru and at one site in the InC. Saccade direction, size, maximum velocity, duration, and latency exhibited the same pattern of dependencies on these stimulation parameters as is illustrated for horizontal saccades in Figure 12. Therefore, the data are not shown. As with tegmentally elicited horizontal saccades, the minimum latency for upward saccades was $19 \mathrm{msec}$.

\section{Fixed-direction saccadic head movements: downward}

Downward saccadic rotations of the head were elicited from 10 sites in the three owls. The locations of these sites are represented by downward arrows in Figures 5-7. The most rostral site was found in owl 2 in the lateral midbrain reticular formation (MRF), lateral to a site associated with upward movements. The relatively lateral locations of downward sites persisted caudally in all three owls to the level of the rhombencephalon, with six sites located in the lateral MRF. Two of these sites were at the lateral edge of the Ru. Another site was within the ventral Ru (Fig. 7C). At the caudalmost tegmental level (Fig. 7D), one site was encountered near the ventral MLF; this was the only downward site that was located on the midline. A second site at this level was located in the lateral MRF, immediately adjacent to upward sites. The remaining two sites were in the tectal efferent bundle.

Effects of initial head position. Figure 15 illustrates the effect of changing initial head position on the trajectories of movements elicited from two different sites. The saccades shown in Figure $15 \mathrm{~A}$ are representative of those having small SDs of direction, while those in Figure $15 B$ have a large SD.

The effect of initial head position on the metrics and kinetics of downward saccades was tested at four sites. As with horizontal and upward sites, the only movement parameter that was predictable across initial head positions and across sites was the direction of the movement (Fig. 16). Mean saccade directions were within $13^{\circ}$ of straight down (polar coordinates; Fig. 3). In contrast to the saccades elicited from horizontal and upward sites, those elicited from downward sites exhibited no strong tendency to alter size or velocity systematically with initial head position. In addition, although the interrelationship of size, maximum velocity, and latency defined a continuous distribution, the clustering apparent for horizontal and upward saccades was less pronounced for downward saccades.

Effects of stimulation parameters. The effects of stimulation current level, pulse frequency, and burst duration were tested at three downward sites. Saccade direction, size, latency, maximum velocity, and duration exhibited the same pattern of dependencies on these stimulation parameters as was observed for horizontal (Fig. 12) and upward saccades. Therefore, the data are not shown. Minimum latencies were as short as $18 \mathrm{msec}$.

\section{Fixed-direction saccadic head movements: roll}

Saccadic rotations around the roll axis (Fig. 17) were elicited from 30 sites in the three owls. At all of the sites, the saccade rolled the head toward the side of the stimulation site, that is, clockwise for sites on the right side of the brain and counterclockwise for sites on the left side. The locations of these sites
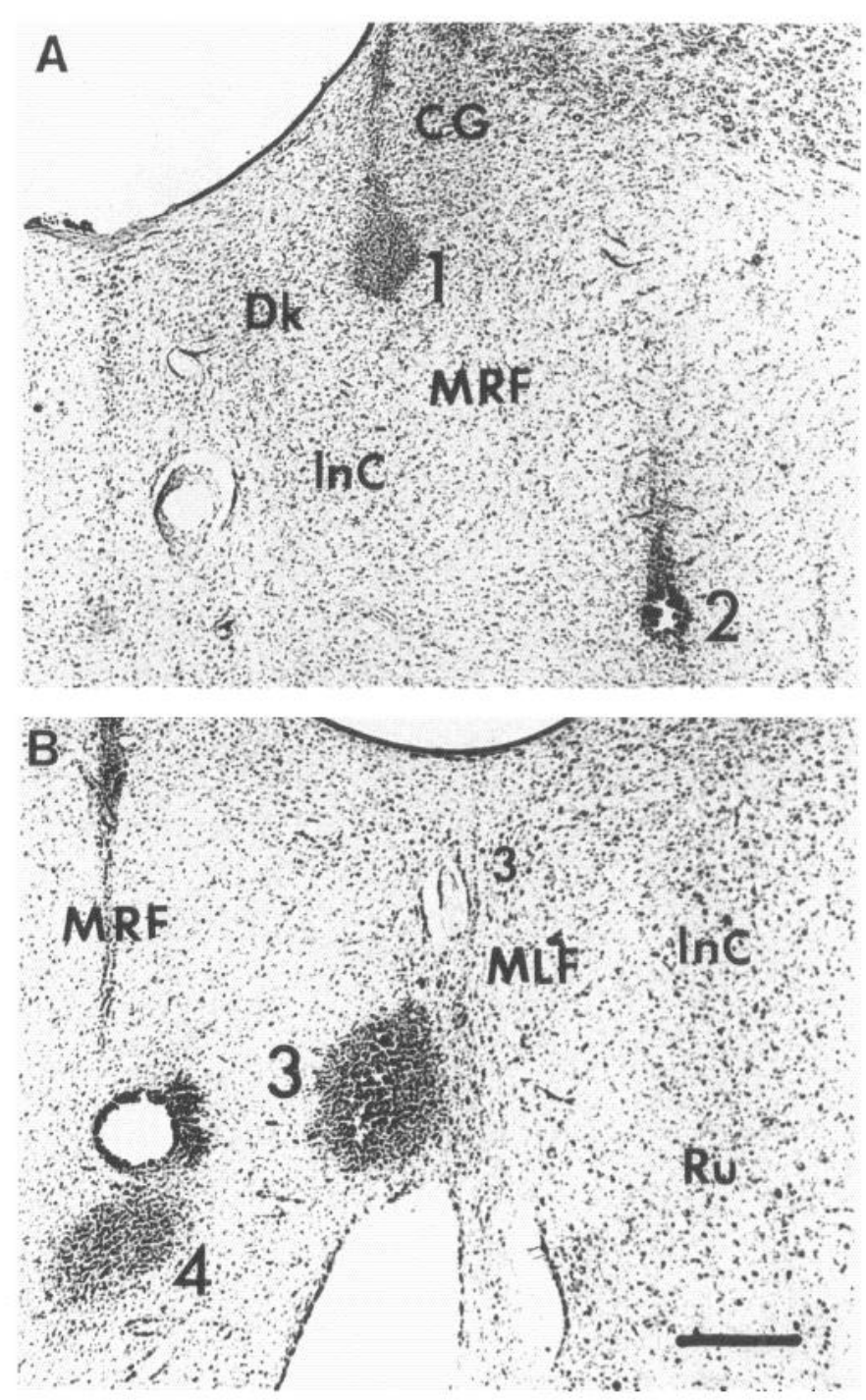

Figure 8. Photomicrographs of Nissl-stained cross sections through the central mesencephalic tegmentum showing lesions at sites from which fixed-direction saccades were elicited. The sections are oriented so that dorsal is up and right is right, etc. $A$. Lesion $l$ is a site that produced rightward fixed-direction saccades. Lesion 2 is a site that produced downward fixed-direction saccades. $B$, Lesion 3 is a site that produced upward fixed-direction saccades, and lesion 4 is a site that produced downward fixed-direction saccades. Scale bar, $500 \mu \mathrm{m}$.

are represented by circular arrows in the camera lucida drawings in Figures 5-7.

The region from which roll saccades were elicited extended farther rostral than the movement zones for the other subclasses of fixed-direction saccades. Four roll sites were in the diencephalon, in and around the OM (Fig. 5A). Farther caudal, most roll sites clustered in the most dorsal portion of the medial midbrain tegmentum, usually above sites that produced horizontal saccades (Figs. $5 A-D, 7 B-D$ ). Many of these sites were localized in the central gray (CG), a region that is outside of the tectospinal overlap region. However, some sites were located among horizontal sites in the InC (Fig. $5 B, C$ ). At more caudal levels (Fig. $7 C, D$ ), roll sites were localized in the $C G$ and one site was found in the lateral portion of the MRF.

Roll movements produced virtually no horizontal (yaw) or vertical (pitch) rotation of the head. In two cases, the search 

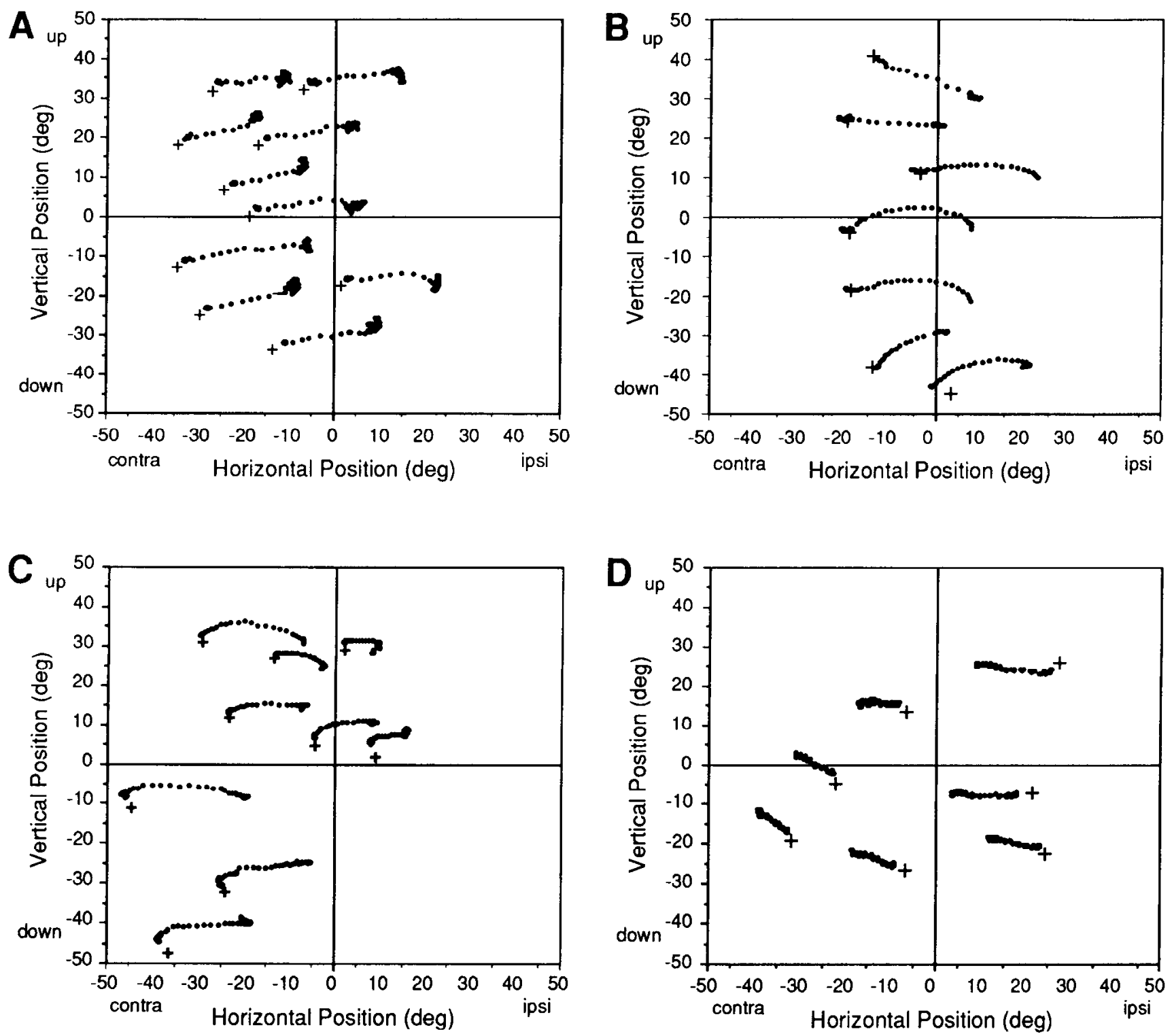

Figure 9. Trajectories of head movements elicited from four sites that produced horizontal fixed-direction saccades. $A-C$, Movements from three medial sites that produced ipsiversive movements. $D$. Contralateral fixed-direction movements elicited from the tectal efferent bundle. The data points represent head position at $5 \mathrm{msec}$ intervals. Trajectory representations and coordinate system are as in Figure 2.

coil was rotated on the head to record the roll movements (see Materials and Methods). Using standard stimulation parameters, roll saccade sizes ranged from $30^{\circ}$ to $75^{\circ}$, maximum velocities ranged from 400 to $700 \% \mathrm{sec}$, and minimum latencies were as low as $20 \mathrm{msec}$. Current levels required to elicit complete roll movements (as low as $15 \mu \mathrm{A}$ ) were generally lower than those required to elicit the other fixed-direction saccades. The effects of initial head position and of varying stimulation parameters were not systematically explored for any roll saccade site.

\section{Goal-directed saccadic head movements}

Goal-directed saccades were elicited from 15 sites in the three owls. All but one of these sites were located in the rhombencephalon and outside of the spinotectal overlap region (Masino and Knudsen, 1992). Goal-directed sites are illustrated for one owl (Fig. 6C,D); site locations are indicated by plus symbols.
Most sites that produced goal-directed movements were located in fiber regions of the rhombencephalic reticular formation (RPo) and in the brachium conjunctivum (DBA). One site was in the deep cerebellar nucleus itself (not shown). In the tegmentum, goal-directed saccades were elicited from sites away from the midline, in the center of the RPo, and out to twothirds of the distance to the lateral edge (the lateral limit of the survey). The region extended from the rostral border of the rhombencephalon rostrally, to the level of the vestibular nuclei caudally (the caudal limit of the survey).

Effect of initial head position. Data from four different goaldirected sites are shown in Figure 18. For clarity, the elicited movements are represented as line segments indicating the initial and final positions of the head. Actual movement trajcctories for a fifth goal-directed site can be seen in Figure $2 B$. As is inherent to the definition of this subclass of saccadic movement, initial head position had a dramatic effect on the direction and size of the evoked movement (Fig. 2C). At some sites, the effect 

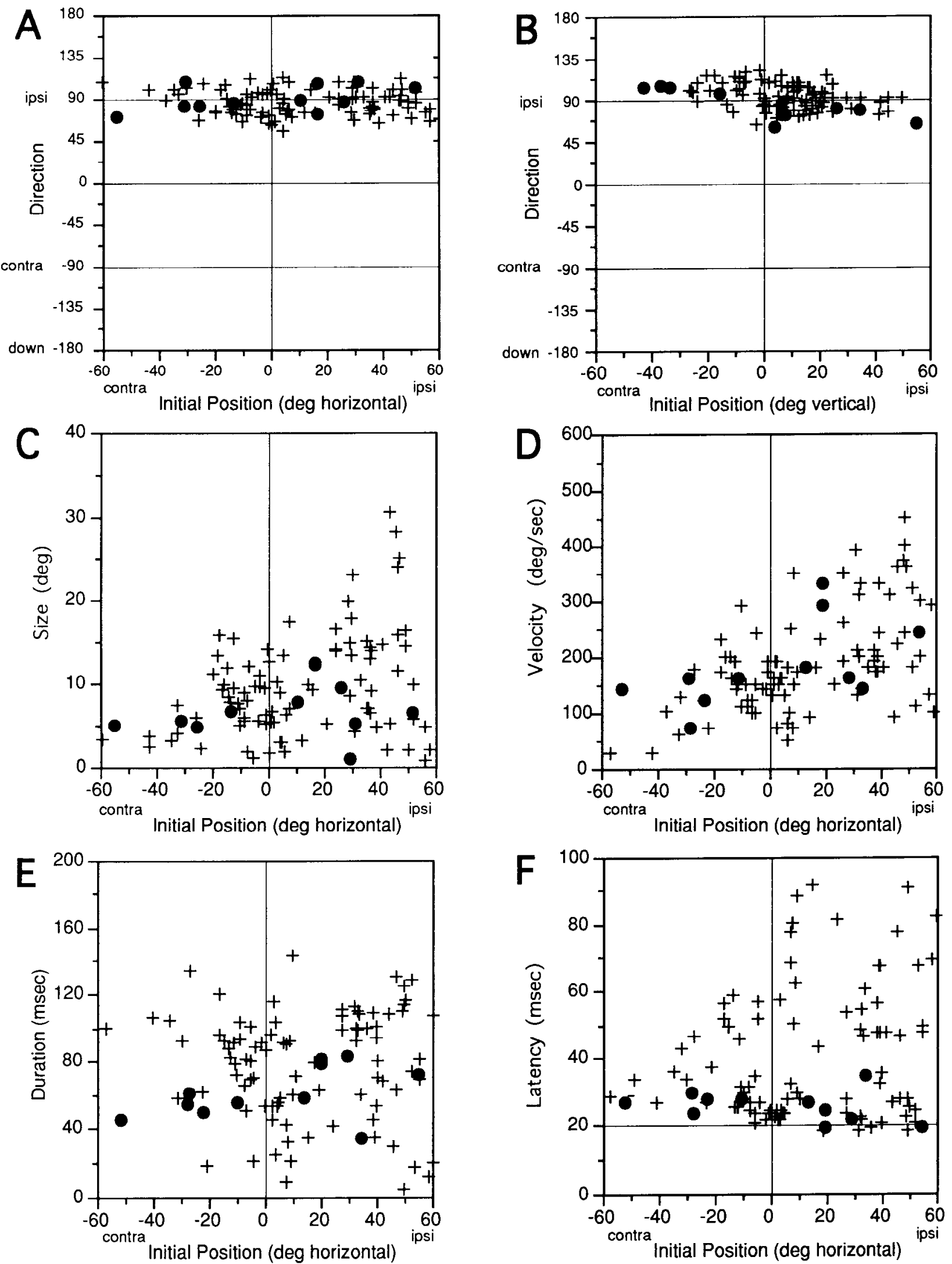

Figure 10. Effect of initial head position on the metrics and kinetics of fixed-direction horizontal saccades. The plots are based on data from movements elicted from 18 horizontal movement sites: circles represent data from a single site; pluses represent data from the other 17 sites. $A$, Movement direction versus initial horizontal position. Direction (ordinate) is defined in a polar coordinate system in which $0^{\circ}$ is upward, $90^{\circ}$ is ipsiversive, $-90^{\circ}$ is contraversive, and $180^{\circ} /-180^{\circ}$ is downward. Initial position (abcissa) is defined as in Figure 3. $B$, Movement direction versus initial vertical position. $C$, Movement size versus initial horizontal position. Size is in degrees of rotation in the direction of movement. $D$, Maximum movement velocity versus initial horizontal position. $E$, Movement duration versus initial horizontal position. $F$, Movement latency versus initial horizontal position. 
Figure 11. Covariation of movement parameters for horizontal fixed-direction movements measured across all initial head positions in all three owls. As movement size increases, maximum velocity increases and movement onset latency decreases. Shaded circles represent data from a single site; solid circles represent data from 17 other sites.

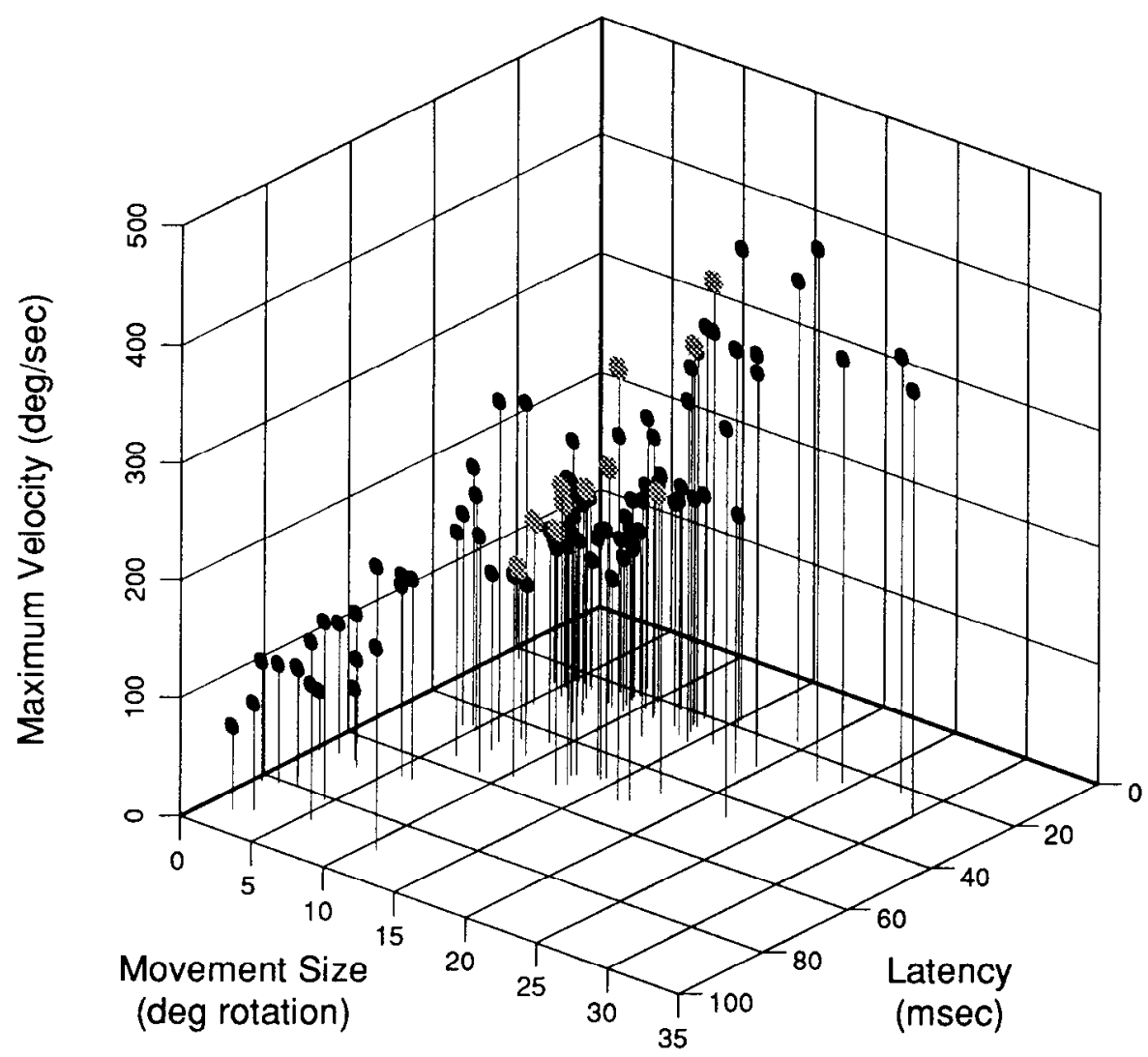

was systematic (Fig. 18A,D): saccades tended to bring the head to a fairly well defined position relative to the body regardless of initial head position. At other sites, the goal head position was poorly defined (Fig. 18B). Nevertheless, saccade direction could be reversed relative to the horizontal and/or vertical planes with changes in initial head position. At five sites, an interesting variant of the goal-directed subclass was observed: saccade direction was limited to a restricted range. In the example shown in Figure $18 C$, no ipsiversive saccades were made. In the example shown in Figure 18D, upward saccades were made only when the head started from a downward position; no movements were made when the head started from an upward position.

Figure $19, A$ and $B$, shows, in contrast to the fixed-direction saccades, the large dependency of movement direction as a function of initial head position. Also, as would be expected from goal-directed saccades, movement size varied systematically with initial head position (Fig. 19C,D).

Effect of stimulation parameters. The effect of varying stimulation parameters was tested at three goal-directed sites. Current level, pulse frequency, and burst duration affected goaldirected saccades in the same way that they affected fixed-direction saccades (Fig. 12): with initial head position held constant, saccade size, maximum velocity, and duration correlated positively and saccade latency correlated negatively with each of these stimulation parameters.

Minimum latencies were as short as $15 \mathrm{msec}$, substantially shorter than those for fixed-direction saccades. Maximum velocities tended to be high (up to $1200 \%$ sec) compared with those of fixed-direction saccades of equivalent size.

\section{Discussion}

The results presented here support the hypothesis that a fundamental transformation in the neural representation of orienting movements takes place in the brainstem tegmentum. Electrical microstimulation in the brainstem of the barn owl elicits two different kinds of orienting head movements: fixeddirection saccades, which are elicited primarily from midbrain sites and which maintain a constant direction independent of initial head position; and goal-directed saccades, which are elicited from rhombencephalic sites and which change direction with changes in initial head position. Stimulation in medial portions of the midbrain tegmentum evokes fixed-direction saccades in one of six directions: leftward, rightward, upward, downward, clockwise roll, or counterclockwise roll. The discreteness and orthogonality of these directions suggest that at the level of the midbrain tegmentum orienting movements are encoded in a head-centered Cartesian frame of reference. The discussion that follows presents the experimental basis for this hypothesis and explores the implications of such a transformation.

\section{Limitations of the microstimulation technique}

The results of this study must be interpreted with an awareness of the limitations of microstimulation. The anatomical localization of stimulation sites must allow for uncertainty about the spread of current. The pattern of current spread was probably irregular due to the heterogeneity of the tissue in the tegmentum; a differential spread of current back up the low-impedance path formed by the electrode track was probably typical. The extent 

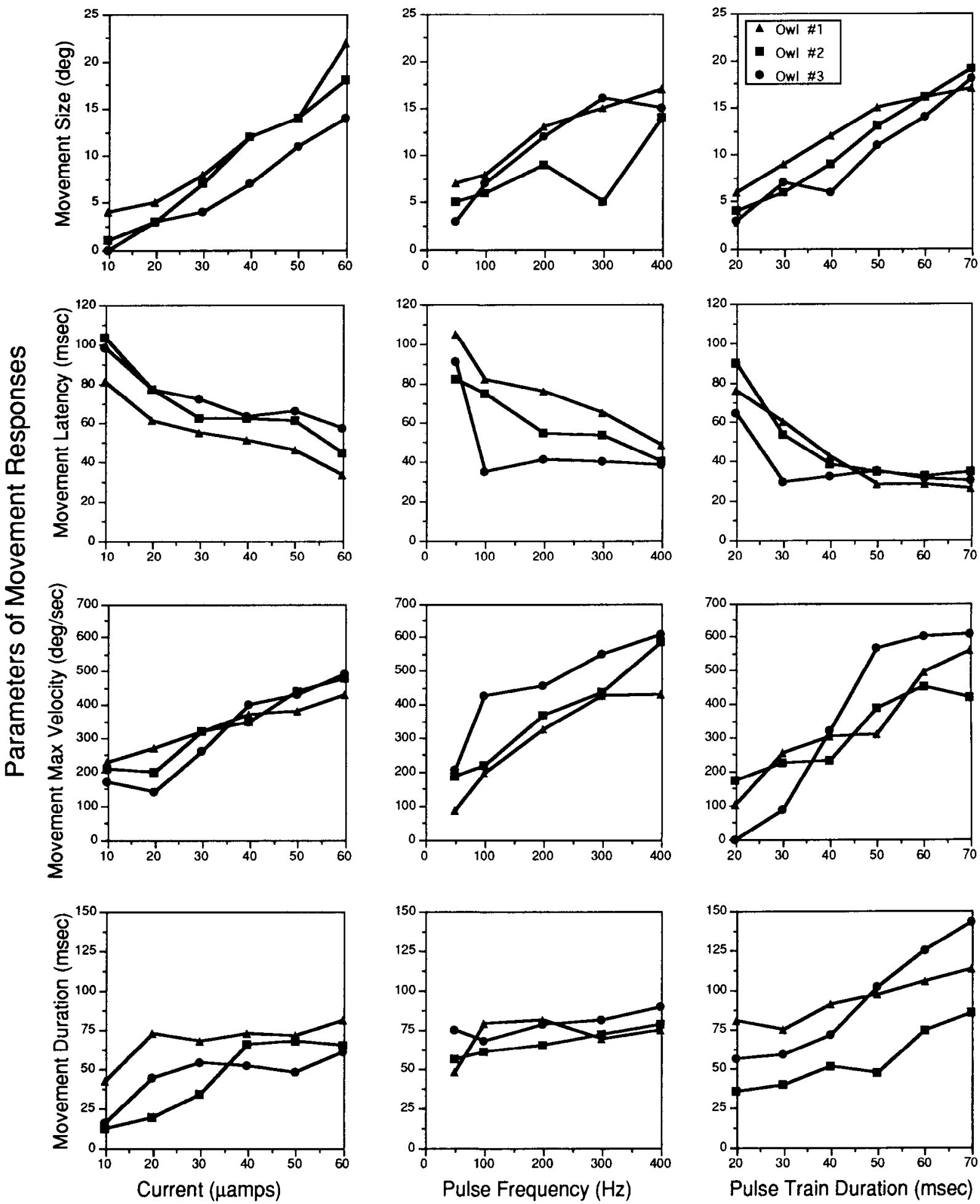

Parameters of Microstimulation

Figure 12. Dependency of movement parameters on parameters of stimulation for three sites that produced horizontal fixed-direction saccades. Circles and squares represent data from two sites in the InC from owls 2 and 3, respectively; triangles represent data from a site lateral to the InC in owl 1. Similar relationships were observed for saccades elicited from upward and downward fixed-direction sites.

of current spread for a given nominal current level also would have been affected by local variations in the resistivity of the tissue. In addition, low current microstimulation activates axons of passage as well as axons that originate at the site of stimulation
(Yeomans, 1990). Furthermore, characterizations of the kinetics and metrics of movements must take into account the fact that the spatial and temporal patterns of neuronal activity induced by microstimulation were probably highly abnormal. Moreover, 

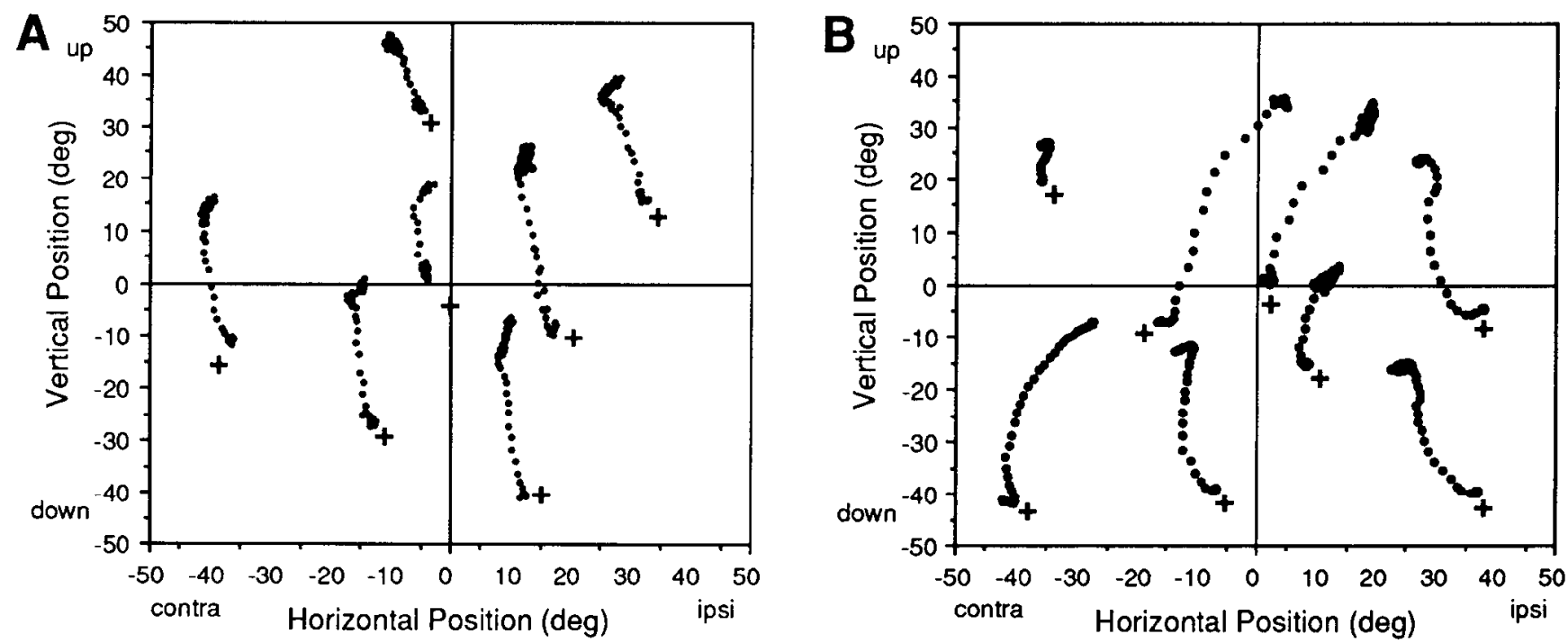

Figure 13. Trajectories of movements from two sites that produced upward fixed-direction saccades. Trajectory representations and coordinate system are as in Figure 2. The site in $A$ was located in the ventral InC; the site in $B$ was located in the medial Ru.

the kinetics and metrics of movements were affected by arousal state, which varied substantially over time.

\section{Movements elicited by tegmental stimulation}

Microstimulation in the brainstem tegmentum elicited one of six classes of motor output depending on the site of stimulation: head saccades, head translations, facial movements, vocalizations, limb movements, or twitches. Considering the uncertainties of current spread, it is remarkable that these different classes of movement were not coexpressed. Vocalizations were not elicited together with head translations, nor were facial movements elicited together with head saccades, and so on. The most striking examples of selective expression were from fixed-direction saccade sites in the medial midbrain tegmentum: advancing the electrode by as little as $50 \mu \mathrm{m}$ could result in an abrupt change in the direction of the elicited saccade from horizontal to up- ward, for example. Although owls naturally make saccades that contain both of these components, the microstimulation technique applied to the medial tegmental regions did not elicit diagonal saccades. This aspect of the results indicates either that the extent of effective current spread was quite small (on the order of $50 \mu \mathrm{m}$ ) or, possibly, that activation of one movement zone in some way suppressed the activation of other movement zones representing different classes or subclasses of movement.

Another remarkable aspect of the results was the natural appearance of certain classes of stimulation-induced movement. Twitches and upper and lower limb movements appeared to be fragments of movement. However, head translations, saccadic head rotations, facial movements, and vocalizations are movements that require spatially and temporally coordinated contractions of many muscle groups. Given the highly unnatural spatial and temporal pattern of activity induced by microstimu-
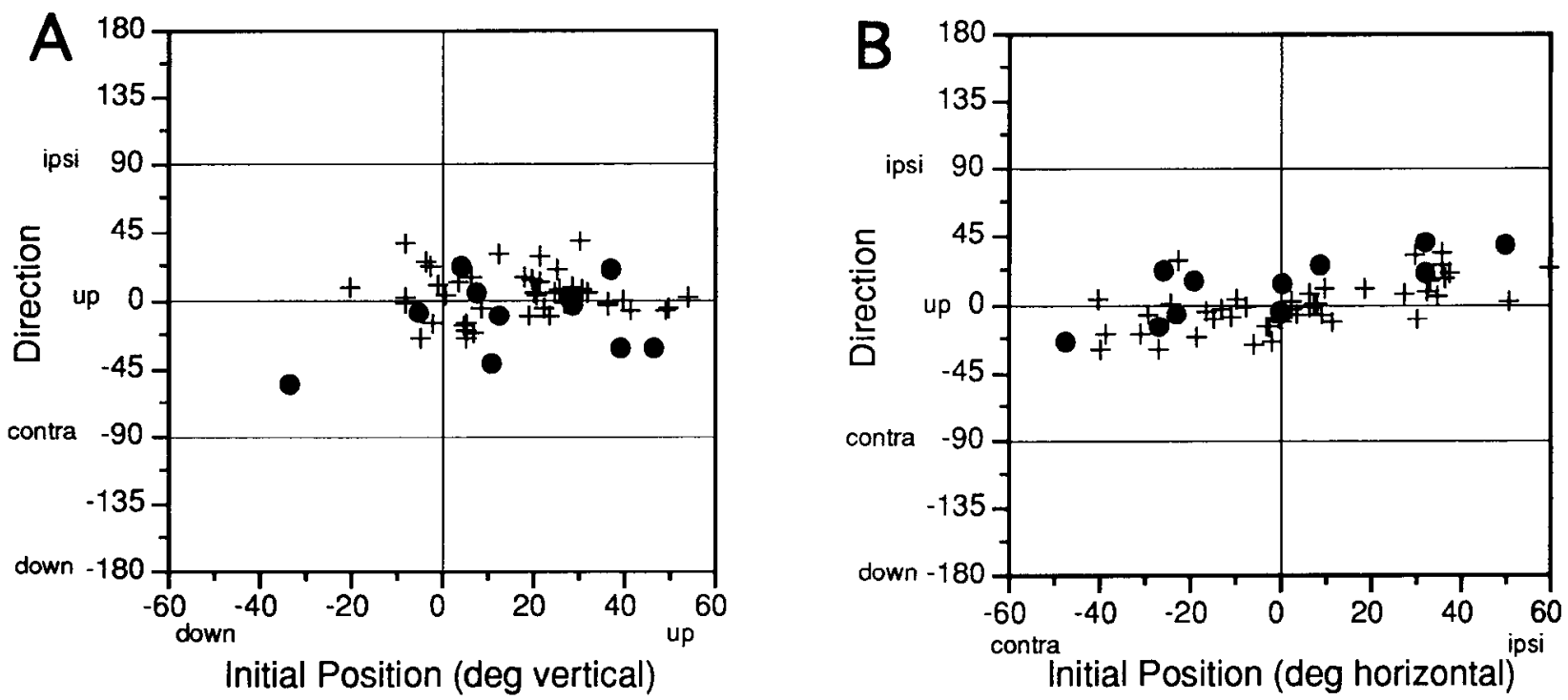

Figure 14. The dependency of movement direction on initial head position for upward fixed-direction saccades. Pluses represent data from seven movement sites; the circles represent data from a single site. Conventions are as in Figure $10, A$ and $B$. $A$, Movement direction (polar coordinates: $0^{\circ}$, up; $90^{\circ}$, ipsiversive; etc.) versus initial vertical position. $B$, Movement direction versus initial horizontal position. 

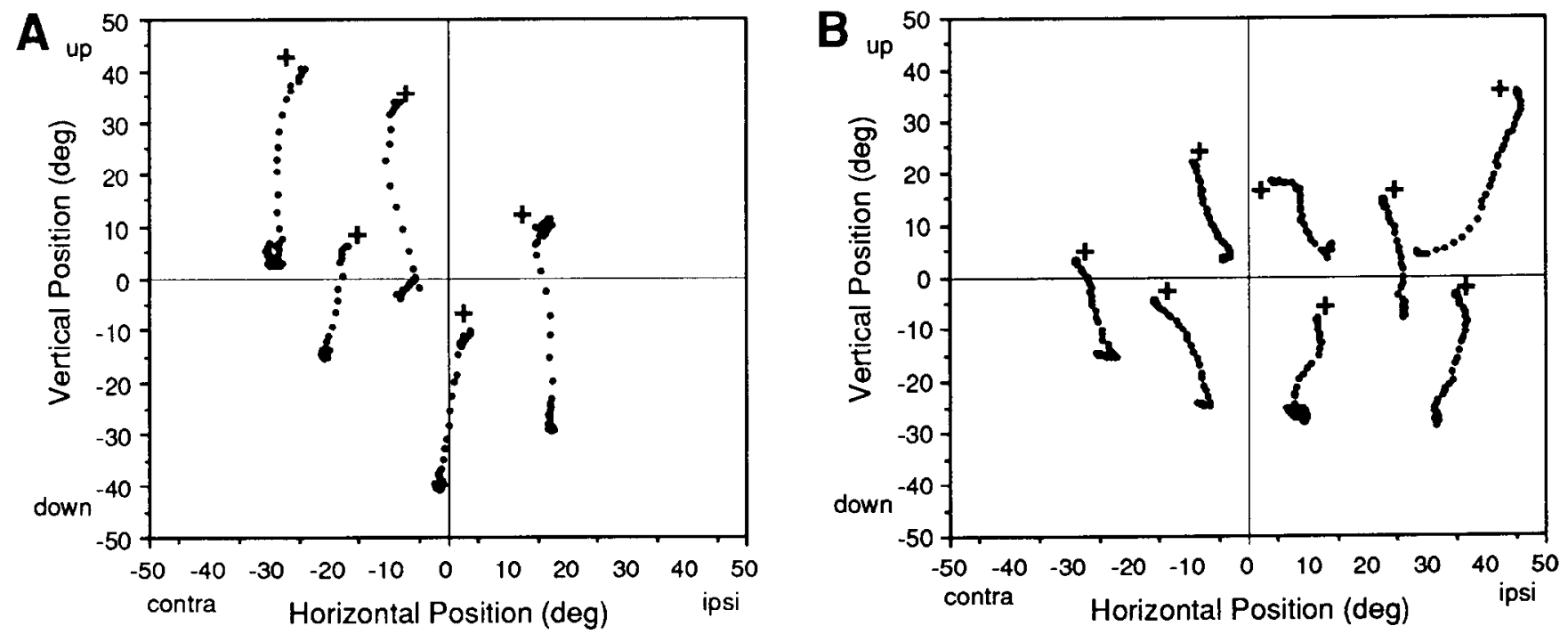

Figure 15. Trajectories of movements from two sites that produced downward fixed-direction saccades. Trajectory representations and coordinate system are as in Figure 2. $A$ shows examples of downward movements that had the smallest SD of direction (SD $=9.7)$. $B$ shows examples of movements that had the largest $\mathrm{SD}$ of direction $(\mathrm{SD}=18.42)$.

lation, this implies that much of the circuitry that orchestrates the coordination of these movements is downstream from the tegmental stimulation sites and that the stimulation is activating a command to initiate these coordinated movements.

\section{Fixed-direction saccades evoked from the midbrain tegmentum}

Head saccades elicited from the midbrain tegmentum always moved the head in the same direction regardless of initial head position. This type of saccade is typical of eye saccades elicited in cats from the rostral optic tectum (Mcllwain, 1986) and in monkeys from the optic tectum (Robinson, 1972), frontal eye fields (Schlag and Schlag-Rey, 1987), and visual cortex (McIlwain, 1988). Although initial position did not affect the direction of the saccades, it usually did affect their size and maximum velocity: the farther the initial position was in the direction of the induced saccade, the smaller and slower tended to be the movement (Fig. 10C,D). This effect probably results, in part, from the length-tension properties of muscles: the more a muscle is contracted, the less the force produced by that muscle for a given increment in motor neuron activity (Rack and Westbury, 1969). Such nonlinearities in the force generated by muscles depending on their state of contraction must be compensated for by the circuitry that normally generates saccades so that their metrics and kinetics remain independent of initial position. The absence of such compensation when saccades are elicited by microstimulation would result if information about head position entered the pathway at or before the site of stimulation and, therefore, was disrupted or bypassed by tegmental stimulation.

The midbrain circuits that mediate head saccades appear capable of regulating the metric (size, direction) and kinematic (changes in position over time) aspects of the saccadic move-
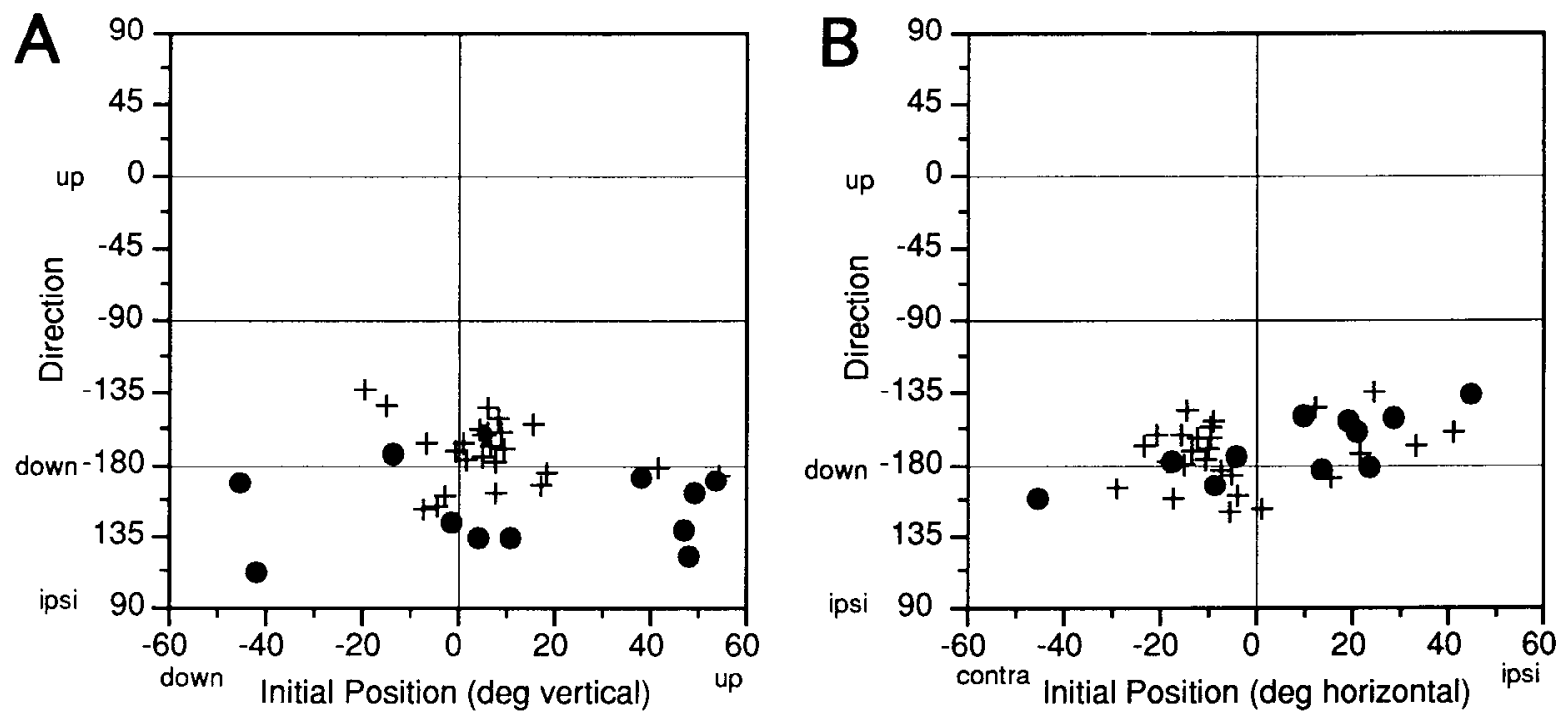

Figure I6. The dependency of movement direction on initial head position for downward fixed-direction saccades. Pluses represent data from 3 movement sites; the circles represent data from a single site. Conventions are as in Figure $10 . A$, Movement direction (polar coordinates) versus initial vertical position. $B$, Movement direction versus initial horizontal position. 


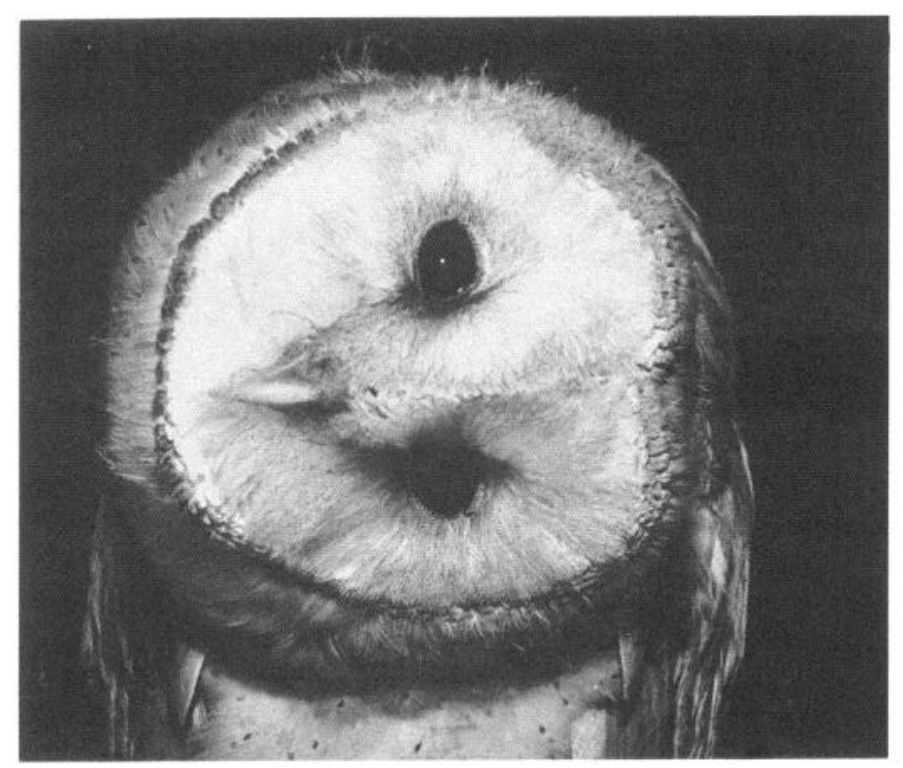

Figure 17. Photograph of a barn owl making a roll movement like those evoked by dorsal mesencephalic tegmental stimulation.

ment. For a given initial head position, the size and velocity of movement covary with stimulation current level, pulse frequency, and train duration (e.g., Fig. 12), implying that these parameters of movement are influenced by the number of spikes occurring per unit of time across a population of fibers in the stimulated zone. It is possible that the spatiotemporal pattern of activity within the circuits is regulated to control movement velocity, amplitude, and latency during coordinated movements.

The directions of fixed-direction head saccades elicited from medial midbrain tegmental sites are discrete and limited to upward, downward, ipsiversive horizontal, and ipsiversive roll. In the rostral midbrain, the regions that produce each saccade direction tend to be relatively large (up to $700 \mu \mathrm{m}$ dorsoventrally) and separable from neighboring regions producing different movement types (Fig. 4). Ipsiversive horizontal movements resulted from activation of the dorsal $\mathrm{InC}$ and regions immediately lateral. Upward movements resulted from activating sites in the ventral $\mathrm{InC}$ and the medial $\mathrm{Ru}$. Downward movement sites were less well clustered than the others, tended to be lateral to the horizontal and upward sites, and were located in the lateral MRF and lateral Ru.

Roll movements resulted from activating the ventral CG and the region just ventral to it in and around the $\mathrm{InC}$ and, farther caudal, the MLF. Rolls may have resulted from activation of the ascending vestibular projection to the $\mathrm{InC}$ and $\mathrm{Ru}$, as these fibers travel in this region on their way to targets in the midbrain (Wild, 1988). Unlike the other fixed-direction saccadic movements, roll movements could also be elicted from thalamic sites that were continuous rostrally with the midbrain sites.

The data are consistent with the hypothesis that, in the medial midbrain tegmentum, saccadic head movements are represented in a Cartesian, head-centered frame of reference by distinct neural circuits controlling, respectively, the leftward, rightward, upward, downward, clockwise roll, and counterclockwise roll components of movement. In the rostral midbrain, the regions producing each type of fixed-direction saccade are anatomically
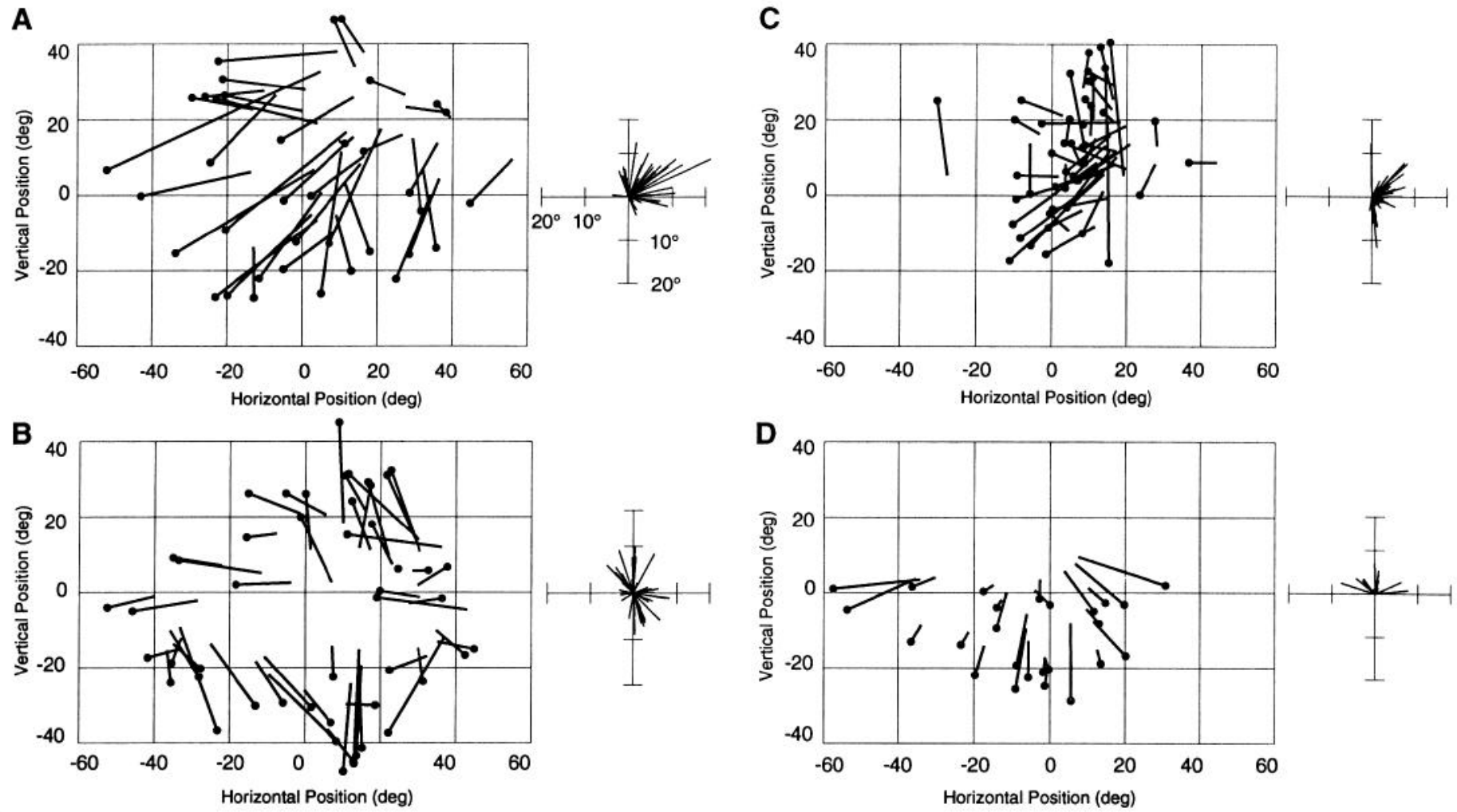

Figure 18. Vector representations of movements elicited from four sites that produced goal-directed saccades. Vectors represent the change in head position between movement onset and offset (see Materials and Methods). The lines indicate the size and direction of each movement with the solid circles representing the initial head position. On the right in each panel, the distribution of movement directions is represented by movement vectors whose initial head positions are aligned at the origin of the coordinate system. 

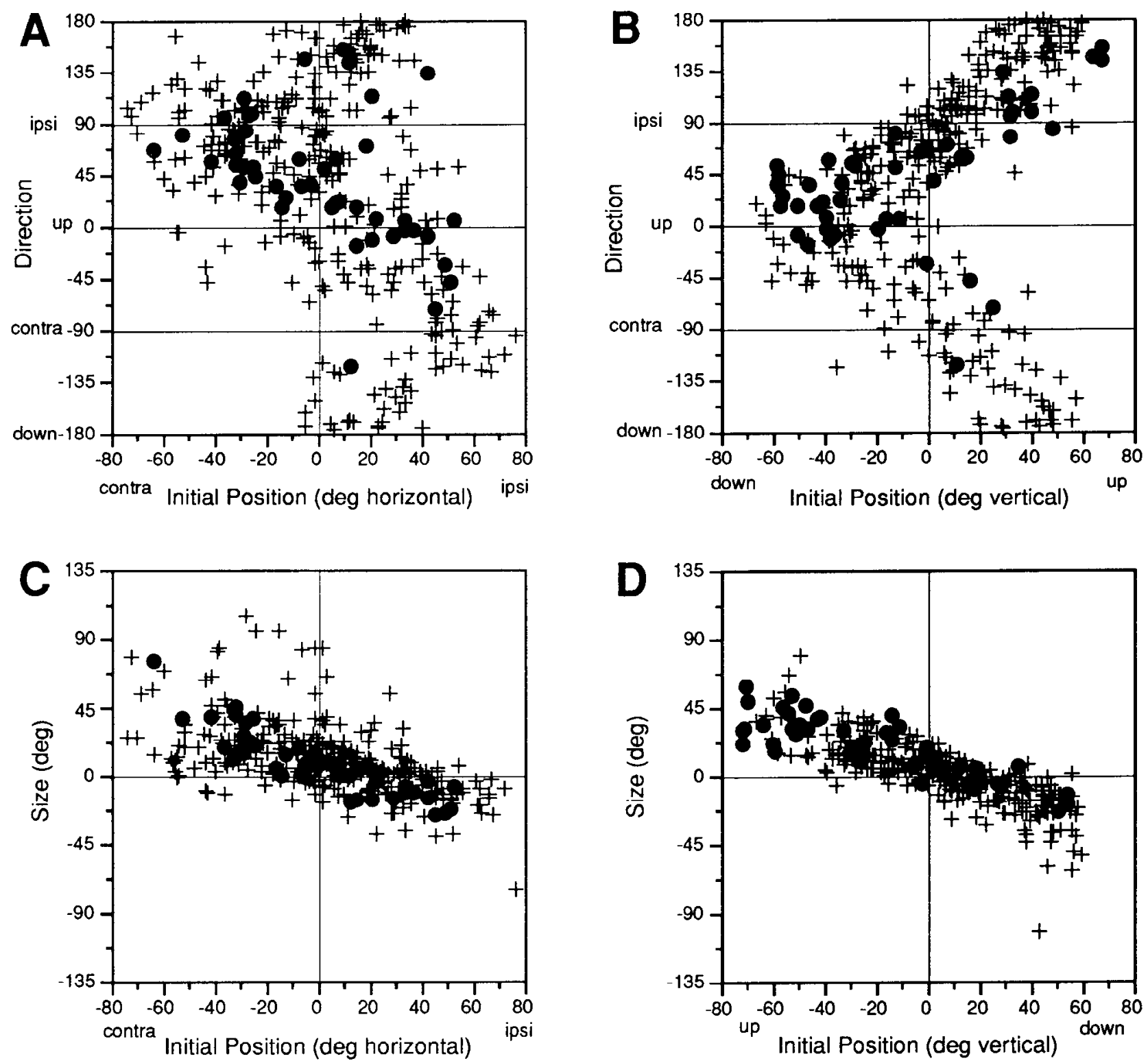

Figure 19. Effect of initial head position on the direction and size of goal-directed saccades. The plots are based on data from movements elicited from 15 goal-directed movement sites: circles represent data from a single site; pluses represent data from the other 14 sites. $A$, Movement direction versus initial horizontal position. Direction (ordinate) is defined in a polar coordinate system in which $0^{\circ}$ is upward, $90^{\circ}$ is ipsiversive, $-90^{\circ}$ is contraversive, and $180^{\circ}-180^{\circ}$ is downward. Initial position (ahscissa) is defined as in Figure 2 . $R$, Movement direction versus initial vertical position. $C$, Movement size versus initial horizontal position. Size is in degrees of rotation in the direction of movement. $D$, Movement size versus initial vertical position.

separate, suggesting that the respective circuits are associated with different cell groups (Masino and Knudsen, 1990). In the caudal midbrain, the movement producing zones are small and intermixed implying that they represent descending fiber tracts.

Although the discreteness of the representation of orthogonal saccade components is clear from the stimulation data, the anatomical identity of the neural elements that participate in the respective circuits is speculative due to the uncertainties inherent to the experimental technique that were discussed previously (see Materials and Methods). Because the stimulation sites in the medial tegmentum are within the path of the tectobulbar fibers, it is possible that the fixed-direction saccades resulted from activating these tectal efferent fibers. However, several lines of circumstantial evidence argue against this possibility.
(1) There is a 2 msec difference in latency between movements elicited by stimulating in the tectal efferent pathway in the lateral tegmentum and those elicited by stimulating fixed-direction sites in the medial tegmentum. (2) Movements elicited by stimulating the tectal efferent bundle in the lateral tegmentum could be initiated from all starting head positions, whereas those elicited by stimulating horizontal sites in the medial tegmentum could not be initiated from most ipsilateral starting head positions (Fig. 9). (3) There was a wide range of movement directions elicited from tectal efferent bundle stimulation, whercas only small ranges of movement direction resulted from more medial stimulation. Nevertheless, direct experimental evidence is necessary to identify positively the structures underlying the fixeddirection saccadic movements observed in this study. 


\section{Goal-directed saccades evoked from the rhombencephalon}

The goal-directed head saccades evoked by stimulating in the central rhombencephalic tegmentum (and in the cerebellar efferent pathway) exhibited the following properties: their direction depended strongly on initial head position, all directions of saccades were possible (even from some individual sites), the goal itself was, with one exception, either frontal or contralateral to the site of stimulation, and the minimum latency of the saccades $(15 \mathrm{msec})$ was substantially shorter than the latency of fixed-direction saccades $(19 \mathrm{msec})$. The saccades are referred to as goal directed, hecause they share the essential characteristics of goal-directed eye saccades elicited in cats and monkeys by stimulating other parts of the brain, including the caudal optic tectum (OT) (Roucoux et al., 1980; McIlwain, 1986), parietal cortex (Shibutani et al., 1984), supplementary frontal eye fields (Schlag and Schlag-Rey, 1987), and cerebellum (Noda, 1991).

It is possible that goal-directed movements are an artifact of the microstimulation paradigm, due perhaps to coactivation of antagonistic movement generators that normally act independently. Alternatively, it is possible that they indicate that, in the medial rhombencephalic tegmentum, head movements are encoded in a body-centered frame of reference (and not in a head-centered frame of reference, as is the case for fixed-direction saccades). The patterns of dependence of saccade direction and sizc on initial head position obscrved for different stimulation sites in the rhombencephalon (Figs. 18, 19) are similar to the range of patterns described for goal-directed eye saccades elicited by stimulating the posterior parietal cortex (Shibutani et al., 1984). Two general categories of motor control circuits could give rise to such goal-directed movements. One kind of circuit interprets the command for movement in the context of current head position, as indicated by corollary discharge or sensory afferent information. The command for movement is transformed by the circuit into different spatial and temporal patterns of activity appropriate to move the head toward the desired position. This kind of circuit is thought to underlie the goal-directed eye movements that are elicited by stimulating the caudal OT in cats (Roucoux et al., 1980; McIlwain, 1986). In the second kind of circuit, the induced focus of neural activity encodes the specific amplitude and timing of excitatory drive delivered to antagonistic sets of muscles. Movement toward the equilibrium position is dictated by these ratios. In this case, information about current head position would not necessarily be involved in the transformation. This kind of circuit is thought to underlie the goal-directed limb movements that result from stimulating premotor areas in the spinal cord of frogs (Bizzi et al., 1991).

\section{Tecto-reticulo-spinal transformations}

Microstimulation and neuroanatomical (Masino, 1992; Masino and Knudsen, 1992) data suggest that a fundamental transformation in the representation of orienting head movements takes place in the rostromedial midbrain tegmentum. In the OT, saccade directions are represented continuously and topographically (du Lac and Knudsen, 1990). Stimulation in the OT or in the tectal efferent bundle (Fig. $5 B$ ) evokes saccades that are contraversive, with minimum latencies as short as $21 \mathrm{msec}$, and with mean directions that can be horizontal, vertical, or diagonal (Fig. 3). Changes in electrode position can result in continuous changes in the mean direction of the saccade.

Anatomical evidence indicates that neurons in the OT project to cells in the region of the rostral midbrain tegmentum where microstimulation produces horizontal and vertical saccades. HRP placed in the tectum results in heavy anterograde labeling in the InC, medial Ru, and MRF (Masino and Knudsen, 1992). Stimulation in these regions (Figs. 5-7) evokes saccades that are ipsiversive, with minimum latencies of $19 \mathrm{msec}$, and with mean directions that can be horizontal, vertical, or roll; diagonal saccades are not evoked. Changes in electrode position within the tegmentum, contrasted with those in the tectum, result either in no change in saccade direction or in an abrupt change to one of the other orthogonal directions.

Four of the directions of movement resulting from activation of the medial tegmentum are similar to those revealed previously by dual-site tectal stimulation experiments (Masino and Knudsen, 1990). These previous experiments indicated that diagonal saccades result from the coactivation of pairs of component generators, each generator controlling movement in either the upward, downward, leftward, or rightward directions. The similarity of the directional components revealed by dualsite tectal stimulation and by tegmental stimulation suggests that the same saccade generator circuitry is being activated in both experiments.

Consistent with the absence of a roll component in tectally elicited saccades, most sites that produce roll saccades are in the $\mathrm{CG}$, an area outside of the tectal projection zone (Masino and Knudsen, 1992).

Each of the regions in the rostral midbrain tegmentum from which fixed-direction head saccades are elicited contain neurons that project directly to the spinal cord. Thus, it is likely that subsequent transformations, such as the translation of the Cartesian code into signals appropriate for the pulling directions of the muscles, may not take place until the level of the spinal cord.

The spatial planes in which the head rotates as a result of stimulating the medial midbrain tegmentum are not those of the semicircular canals. The superior and posterior canals in the barn owl are mutually orthogonal and are oriented at approximately $45^{\circ}$ to the midsagittal and transverse planes. The horizontal canal is oriented approximately $27^{\circ}$ down relative to the visual plane (Masino and Knudsen, unpublished observation). Rotations in one of these planes would contain nearly equal horizontal, vertical, and roll components. Ilowever, vertical rotations elicited from the medial midbrain tegmentum contain no roll and, at hest, a small horizontal component (the horizontal component perhaps being due to unilateral activation of a bilateral neural circuit that normally is activated symmetrically). Similarly, horizontal rotations contain no roll component and little vertical component. Finally, roll rotations contain no apparent horizontal or vertical components. Instead, the planes of rotation are much closer to the planes defined by the visual axes of the eyes (horizontal plane) and the midsagittal plane of the body (vertical plane).

Sites from which horizontal and vertical saccades were elicted are located in the vicinity of ascending vestibulo-mesencephalic projections. Recordings from second-order vestibular neurons in the cat demonstrate that many receive convergent inputs from the semicircular canals (Fukushima et al., 1990; Peterson et al., 1992), suggesting that thesc neurons have at least begun the transformation from vestibular to motor coordinates. Thus, it is possible that ascending vestibular information arriving in the medial midbrain from the medial and superior vestibular nuclei is in an intermediate coordinate space. 
Representation of orthogonal movement components: a general vertebrate strategy

Considering the profound differences in the motor plants for controlling eye versus head movements, the circuitry involved in the transformation of the topographic motor code in the tectum to an orthogonal component representation in the tegmentum appears to be similar in owls and monkeys. The production of owl head saccades and monkey eye saccades both involve medial brainstem tegmental structures. In monkeys, circuits involved in the control of vertical eye saccades have been localized to the (riMLF) (Buttner-Ennever, 1978; Fukushima, 1987; Moschovakis et al., 1990) and prerubral fields (Graybiel, 1977), which are situated just rostral to the InC. In owls, sites eliciting vertical head saccades are localized to a similar region, in the ventral InC and dorsomedial $\mathrm{Ru}$ (the riMLF and prerubral fields have not been defined in avians). However, a discrete representation of ipsiversive horizontal eye saccades has not been found in the midbrain of monkeys. Instead, ipsiversive eye saccades are affected by lesions and stimulation of the PPRF (Raphan and Cohen, 1971; Sparks et al., 1987).

Another apparent difference between circuits controlling monkey eye saccades and owl head saccades is that stimulation of vertical saccade sites in the midbrain tegmentum of the owl produces little or no roll, whereas only bilateral stimulation of certain tegmental sites in primates produces vertical movements, with unilateral stimulation resulting in ipsiversive roll movements (Crawford et al., 1991). However, neurophysiological recordings in monkeys demonstrate that neurons in the InC are maximally active during upward or downward eye saccades and that these upward and downward cells tend to be intermixed (Fukushima, 1987; Moschovakis et al., 1990). Thus, it is possible that stimulation of this region results in antagonistic vertical movement signals, leaving the expression of roll movements from activation of nearby sites. In the barn owl, the cell groups may be more segregated, allowing selective expression of the up, down, and roll components.

It is evident that the code for movement direction in the optic tectum differs substantially from that at tegmental levels. In the owl, previous experiments have shown that it is possible to remove either a horizontal or a vertical component of movement without affecting the expression of the other components (Masino and Knudsen, 1990). Studies of tectal control of orienting movements in the frog demonstrate a posttectal transformation to a similarly parcellated representation of movement in which horizontal turn angle and distance are separable components (Kostyk and Grobstein, 1987; Masino and Grobstein, 1989a,b; Masino, 1992). In both cases, the horizontal signal underlying orienting movements is established in the rostral midbrain and encodes ipsiversive turns.

A similar situation exists for the control of eye saccades in monkeys. Here, too, it is possible to activate selectively circuitry controlling either the horizontal or vertical component of movement (Robinson, 1972). However, because the oculomotor plant itself has an orthogonal character, the existence of an intermediate, abstract motor code is less apparent. Nevertheless, the commonalities among the posttectal circuits subserving such different motor plants (eyes, head, body) in such distantly related species suggest a general strategy in the control of orienting movements in vertebrates: topographic representations of movement are transformed in the medial brainstem tegmentum into an abstract Cartesian code in which separate cell groups represent orthogonal directions of movement.

$\begin{array}{ll}\text { Appendix } \\ 3 & \text { oculomotor nucleus } \\ 4 & \text { trochlear nucleus } \\ 6 & \text { abducens nucleus } \\ \text { AL } & \text { ansa lenticularis } \\ \text { CG } & \text { central gray } \\ \text { Dk } & \text { nucleus Darkschewitsch } \\ \text { DBA } & \text { deccussation of the brachium conjunctivum, anterior } \\ \text { DBC } & \text { deccussation of the brachium conjunctivum, caudal } \\ \text { EW } & \text { Edinger-Westphal nucleus } \\ \text { InC } & \text { interstitial nucleus of Cajal } \\ \text { IP } & \text { interpeduncular nucleus } \\ \text { IS } & \text { nucleus isthmi } \\ \text { LRF } & \text { lateral reticular formation } \\ \text { MRF } & \text { medial reticular formation } \\ \text { MLF } & \text { medial longitudinal fasiculus } \\ \text { n3 } & \text { oculomotor nerve } \\ \text { OM } & \text { occipitomesencephalic tract } \\ \text { OT } & \text { optic tectum } \\ \text { PC } & \text { posterior commissure } \\ \text { PPRF } & \text { paramedian pontine reticular formation } \\ \text { PT } & \text { pretectal nucleus } \\ \text { QF } & \text { quintofrontalis tract } \\ \text { riMLF } & \text { rostral interstitial nucleus of the medial reticular formation } \\ \text { RPgc } & \text { pontine reticular nucleus, gigantocellularis } \\ \text { RPo } & \text { pontine reticular nucleus, oralis } \\ \text { Ru } & \text { red nucleus } \\ \text { SCE } & \text { stratum cellular externum }\end{array}$

\section{References}

Bizzi E, Mussa-Ivaldi FA, Giszter S (1991) Computations underlying the execution of movement: a biological perspective. Science 253 : 287-291.

Buttner-Ennever JA, Buttner U (1978) A cell group associated with vertical eye movements in the rostral mesencephalic reticular formation of the monkey. Brain Res 151:31-47.

Crawford JD, Cadera W, Vilis T (1991) Generation of torsional and vertical eye position signals by the interstitial nucleus of Cajal. Science 252:1551-1553.

du Lac S, Knudsen EI (1990) Neural maps of head movement vector and speed in the optic tectum of the barn owl. J Neurophysiol 63: $131-146$.

Fukushima K (1987) The interstitial nucleus of Cajal and its role in the control of movements of the head and eyes. Prog Neurobiol 29: 107-192.

Fukushima K, Perlmutter SI, Baker JK, Peterson BW (1990) Spatial properties of second-order vestibulo-ocular relay neurons in the alert cat. Exp Brain Res 81:462-478.

Grantyn A, Grantyn R (1982) Axonal patterns and sites of termination of cat superior colliculus neurons projecting in the tecto-bulbar spinal tract. Exp Brain Res 46:243-256.

Graybiel AM (1975) Organization of oculomotor pathways in the cat and rhesus monkey. Dev Neurosci 1:79-88.

Graybiel AM (1977) Direct and indirect preoculomotor pathways of the brainstem: and autoradiographic study of the pontine reticular formation in the cat. J Comp Neurol 175:37-78.

Grobstein P (1988) Between the retinotectal projection and directed movement: topography of a sensorimotor interface. Brain Behav Evol 31:34-48.

Huerta MF, Harting JK (1982) Tectal control of spinal cord activity: neuroanatomical demonstration of pathways connecting the superior colliculus with the cervical spinal cord grey. Prog Brain Res 57:293328.

Keller EL (1974) Participation of medial pontine reticular formation in eye movement generation in monkey. J Neurophysiol 37:316-332.

Kostyk SK, Grobstein P (1987) Neuronal organization underlying visually elicited prey orienting in the frog. I. Effects of various unilateral lesions. Neuroscience 24:41-55. 
Masino T (1992) Brainstem control of orienting movements: intrinsic coordinate systems and underlying circuitry. Brain Behav Ecol, in press.

Masino T, Grobstein P (1989a) The organization of descending tectofugal pathways underlying orienting in the frog, Rana pipiens: 1 . Lateralization, parcellation and an intcrmediate spatial representation. Exp Brain Res 75:227-244.

Masino T, Grobstein P (1989b) The organization of descending tectofugal pathways underlying orienting in the frog, Rana pipiens: 2. Evidence for the involvement of a tecto-tegmento-spinal pathway. Exp Brain Res 75:245-264.

Masino T, Grobstein P (1990) Tectal connectivity in the frog, Rana pipiens: tectotegmental connections an a general analysis of topographic organization. J Comp Neurol 291:103-127.

Masino T, Knudsen EI (1990) Distinct neural circuits control horizontal and vertical components of head movement in the barn owl. Nature 345:434-437.

Masino T, Knudsen EI (1992) Anatomical pathways from the optic tectum to the spinal cord subserving orienting movements in the barn owl. Exp Brain Res, in press.

McIlwain JT (1986) Effects of eye position on saccades evoked electrically from superior colliculus of alert cats. J Neurophysiol 55:97112.

Mcllwain JT (1988) Saccadic eye movements evoked by electrical stimulation of the cat's visual cortex. Vis Neurosci 1:135-143.

Moschovakis AK, Scudder CA, Highstein SM (1990) A structural basis for Hering's law: projections to extraocular motorneurons. Science 248:1118-1119.

Munoz DP, Pellison D, Guitton D (1991) Movement of neural activity on the superior colliculus motor map during gaze shifts. Science 251: $1358-1360$.

Noda H (1991) Cerebellar control of saccadic eye movements: its neural mechanisms and pathways. Jpn J Physiol 41:351-368.

Peterson BW, Baker JF, Perlmutter SI, Iwamoto Y (1992) Neuronal substrates of spatial transformations in vestibuloocular and vestibulocolic reflexes. In: Ann NYAS (Cohen B, Tanko D, Guedry F, eds), $656: 485-489$.
Rack PMH, Westbury DR (1969) The effects of length and stimulus rate on tension in the isometric cat soleus muscle. J Physiol (Lond) 268:443-460.

Ranck JB (1980) Extracellular stimulation. In: Electrical stimulation research techniques (Patterson $M$, Keshner R, eds), pp 1-36. New York: Academic.

Raphan T, Cohen B (1971) Brainstem mechanisms for rapid and slow eye movements. J Neurophysiol 34:920-936.

Robinson DA (1972) Eye movements evoked by collicular stimulation in the alert monkey. Vision Res 12:1795-1808.

Roucoux A, Guitton D, Crommelinck M (1980) Stimulation of the superior colliculus in the alert cat: 1 . Eye movements and neck EMG activity evoked when the head is unrestrained. Exp Brain Res 39:7585.

Schaefer K-P, Schott D, Meyer DL (1975) On the organization of neuronal circuits involved in the generation of the orientation response (visual grasp reflex) (1). Fortshr Zool 23:199-212.

Schlag J, Schlag-Rey M (1987) Evidence for a supplementary eye field. J Neurophysiol 57:179-200.

Shibutani H, Sakata H, Hyvarinen J (1984) Saccade and blinking eye movements evoked by microstimulation of the posterior parietal association cortex of the monkey. Exp Brain Res 55:1-8.

Sparks DL (1986) Translation of sensory signals into commands for control of saccadic eye movements: role of primate superior colliculus. Physiol Rev 66:118-171.

Sparks DL, Mays LE (1983) Spatial localization of saccade targets I. Compensation for stimulus-induced perturbations in eye position. $\mathrm{J}$ Neurophysiol 49:45-63.

Sparks DL, Mays LE, Porter JD (1987) Eye movements induced by pontine stimulation: interaction with visually triggered saccades. $\mathrm{J}$ Neurophysiol 58:300-318.

Wild JM (1988) Vestibular projections to the thalamus of the pigeon: an anatomical study. J Comp Neurol 271:451-460.

Yeomans JS (1990) Principles of brain stimulation. New York: Oxford UP. 